\title{
Two-dimensional model simulations of the QBO in ozone and tracers in the tropical stratosphere
}

\author{
Eric L. Fleming, ${ }^{1}$ Charles H. Jackman, and Joan E. Rosenfield ${ }^{2}$ \\ NASA Goddard Space Flight Center, Greenbelt, Maryland, USA
}

David B. Considine

NASA Langley Research Center, Hampton, Virginia, USA

Received 24 July 2001; revised 25 February 2002; accepted 20 June 2002; published 3 December 2002.

[1] Meteorological data from the United Kingdom Meteorological Office (UKMO) and constituent data from the Upper Atmospheric Research Satellite (UARS) are used to construct yearly zonal mean dynamical fields for the 1990s for use in the NASA/Goddard Space Flight Center (GSFC) two-dimensional (2-D) chemistry and transport model. This allows for interannual dynamical variability to be included in the model constituent simulations. In this study, we focus on the tropical stratosphere. We find that the phase of quasi-biennial oscillation (QBO) signals in equatorial $\mathrm{CH}_{4}$ and profile and total column $\mathrm{O}_{3}$ data are resolved quite well using this empirically based 2-D model transport framework. However, the QBO amplitudes in the model constituents are systematically

underestimated relative to the observations at most levels. This deficiency is probably due in part to the limited vertical resolutions of the 2-D model and the UKMO and UARS input data sets. We find that using different heating rate calculations in the model affects the interannual and QBO amplitudes in the constituent fields, but has little impact on the phase. Sensitivity tests reveal that the QBO in transport dominates the ozone interannual variability in the lower stratosphere, with the effect of the temperature QBO being dominant in the upper stratosphere via the strong temperature dependence of the ozone loss reaction rates. We also find that the $\mathrm{QBO}$ in odd nitrogen radicals, which is caused by the QBO modulated transport of $\mathrm{NO}_{y}$, plays a significant but not dominant role in determining the ozone QBO variability in the middle stratosphere. The model mean age of air is in good overall agreement with that determined from tropical lower-middle stratospheric OMS balloon observations of $\mathrm{SF}_{6}$ and $\mathrm{CO}_{2}$. The interannual variability of the equatorial mean age in the model increases with altitude and maximizes near $40 \mathrm{~km}$, with a range of 4-5 years over the 1993-2000 time period. INDEX TERMS: 0341 Atmospheric Composition and Structure: Middle atmosphere — constituent transport and chemistry (3334); 3334 Meteorology and Atmospheric Dynamics: Middle atmosphere dynamics (0341, 0342); 3337 Meteorology and Atmospheric Dynamics: Numerical modeling and data assimilation; 3319 Meteorology and Atmospheric Dynamics: General circulation; KEYWORDS: interannual variability, stratospheric circulation, ozone

Citation: Fleming, E. L., C. H. Jackman, J. E. Rosenfield, and D. B. Considine, Two-dimensional model simulations of the QBO in ozone and tracers in the tropical stratosphere, J. Geophys. Res., 107(D23), 4665, doi:10.1029/2001JD001146, 2002.

\section{Introduction}

[2] The quasi-biennial oscillation (QBO) is the dominant mode of interannual variability in the tropical lower stratosphere. Since its discovery by Reed et al. [1961] and Veryard and Ebdon [1961], there have been numerous observational studies documenting the QBO in zonal wind and temperature [e.g., Reed, 1964; Angell and Korshover,

\footnotetext{
${ }^{1}$ Also at Science Systems and Applications, Inc., Lanham, Maryland.

${ }^{2}$ Also at Goddard Earth Sciences and Technology Center, University of Maryland Baltimore County, Baltimore, Maryland.

Copyright 2002 by the American Geophysical Union. 0148-0227/02/2001JD001146\$09.00
}

1970; Dunkerton and Delisi, 1985; Naujokat, 1986; Nash, 1988; Ortland et al., 1996; Dunkerton, 1997; Randel et al., 1999; Baldwin et al., 2001]. The associated QBO signal in the meridional circulation gives rise to a QBO variation in ozone and long-lived trace species [e.g., Hasebe, 1994; Eluszkiewicz et al., 1996; Cordero et al., 1997; O'Sullivan and Dunkerton, 1997; Randel et al., 1998; Dunkerton, 2001]. Additionally, the effect of the QBO on the circulation and constituent distributions in the extratropics has been investigated in a variety of studies [e.g., Holton and Tan, 1980; Lait et al., 1989; Bowman, 1989; Randel and Cobb, 1994; Tung and Yang, 1994; O'Sullivan and Dunkerton, 1997; Gray and Russell, 1999; Randel et al., 1998; Kinnersley and Tung, 1999; Randel et al., 1999]. 
[3] The tropical upper stratosphere is characterized by a dominant semiannual oscillation (SAO) signal in wind and temperature [e.g., Garcia et al., 1997, and references therein], and long-lived tracers [e.g., Choi and Holton, 1991; Randel et al., 1994]. The upper stratospheric SAO in the circulation and tracer distributions are also thought to be modulated by the QBO variations in the underlying lower stratospheric winds [e.g., Ruth et al., 1997; Kennaugh et al., 1997].

[4] Various modeling studies have investigated the processes that control the QBO and SAO responses in stratospheric ozone and constituent distributions. Gray and Pyle [1987] used an interactive two-dimensional (2-D) model with a parameterization of momentum transfer to the zonal flow from dissipating equatorial Kelvin waves to examine the stratospheric semiannual oscillation. Their model qualitatively reproduced a SAO in zonal wind, and a "double peaked" structure in the tracer fields associated with the SAO meridional circulation. These authors extended this work to include parameterizations of Kelvin and RossbyGravity waves associated with the lower stratospheric QBO [Gray and Pyle, 1989]. Although their simulations did not correspond to a particular time period and generated a near constant QBO period, they were able to reproduce many qualitative aspects of the QBO in zonal wind, temperature, and total ozone. Gray and Dunkerton [1990] then investigated the interaction of the QBO with the seasonal cycles in each hemisphere, and successfully reproduced several of the basic features of the ozone QBO in the tropics and subtropics in their 2-D interactive model. Subsequent studies discussed the QBO signal in various trace gases generated in the model simulations [Gray and Chipperfield, 1990; Chipperfield and Gray, 1992].

[5] Gray and Ruth [1993] followed these investigations by simulating a QBO in their 2-D model for the specific years $1971-1990$ by relaxing the model equatorial winds to observations. The resulting QBO signal in the total ozone simulation agreed reasonably well with satellite observations. These authors also discussed the importance of the QBO interaction with the annual cycle in determination of the ozone anomalies in the subtropics. In a related study, Jones et al. [1998] used a 2-D interactive model to investigate the QBO and seasonal dependence on the tracer transport in the tropics and subtropics.

[6] Simulations of QBO variations have also been recently performed using 3-D models. Nagashima et al. [1998] simulated a QBO in ozone using a general circulation model (GCM). The resulting model amplitude of the lower stratospheric ozone QBO was somewhat less than observed, with a mostly realistic phase reversal of the signal in the upper stratosphere. Hamilton et al. [1999], using high vertical resolution in the GFDL SKIHI GCM, obtained a spontaneous, internally generated oscillation in the equatorial stratospheric zonal winds which closely resembled a QBO-type oscillation, but with a period less than half of the observed QBO.

[7] The interaction of the QBO and SAO has also been investigated by Kennaugh et al. [1997] using a 2-D isentropic model. They found that the lower stratospheric QBO modulates the strength of the upper stratospheric SAO circulation, consistent with the interannual changes seen in $\mathrm{CH}_{4}$ measurements made by the Halogen Occultation
Experiment (HALOE) onboard the Upper Atmospheric Research Satellite (UARS). These authors discuss the subtle ways in which the time-integrated vertical motion affects the depth of the double-peaked structure in upper stratospheric $\mathrm{CH}_{4}$.

[8] Our 2-D chemistry and transport model at NASA/ Goddard Space Flight Center (GSFC) has been widely used in scientific and assessment studies of the long term changes in stratospheric ozone [e.g., Jackman et al., 1996; World Meteorological Organization (WMO), 1999]. Incorporating interannual dynamical variability in the model is important to more fully understand past ozone changes and the future ozone recovery [WMO, 1999; Chipperfield, 1999]. We previously examined the impact of interannual variability on our model ozone field using an earlier version of the model transport formulation [Jackman et al., 1991]. This model was able to simulate a good deal of the interannual variability in upper stratospheric ozone at low to middle latitudes where temperature dependent photochemistry controls the ozone distribution. However, this previous model did not resolve the observed QBO in total column ozone.

[9] We have recently upgraded the formulation for deriving our empirical 2-D model transport fields from meteorological data sets. For climatological conditions, this new methodology gives good model agreement with a variety of ozone and long-lived tracer measurements [Fleming et al., 1999]. In light of this, we have extended the new formulation to allow for interannual dynamical variations in the model simulations. For this we use the global winds and temperatures from the United Kingdom Meteorological Office (UKMO) data assimilation system for the specific years 1992-2000. Recent analysis has shown that the UKMO data provide a reasonably good representation of the QBO and SAO features in the tropical stratosphere during the 1990s, although the respective amplitudes are underestimated [Randel et al., 1999; Dunkerton, 2000]. In this study, we compute diabatic heating rates and the Eliassen-Palm flux divergence directly from the UKMO data to obtain the residual circulation and eddy diffusion fields on a global basis for our 2-D model transport. Our modeling approach for including interannual variability therefore differs from previous interactive 2-D model studies, for example, those that imposed a QBO by relaxing the model lower stratospheric equatorial winds to observations and allowing the model circulation to respond globally [e.g., Gray and Ruth, 1993; Kinnersley and Tung, 1999], or studies that additionally imposed extratropical interannual variability by forcing the model with the observed planetary wave heights at the tropopause [Kinnersley and Tung, 1998]. Details of our model transport methodology are contained in section 2 .

[10] In the present paper, we focus on the tropical stratosphere where the zonal mean constituent distributions are controlled primarily by the residual circulation with eddy diffusion processes being much less important. Previous analysis has shown that in this region, our empirically based climatological 2-D model framework does a good job in simulating the age of air and seasonal cycle propagation [Hall et al., 1999; Fleming et al., 1999]. Here we extend this analysis to interannual timescales and examine how much of the observed year to year constituent variability in the tropics can be explained in our model utilizing the 

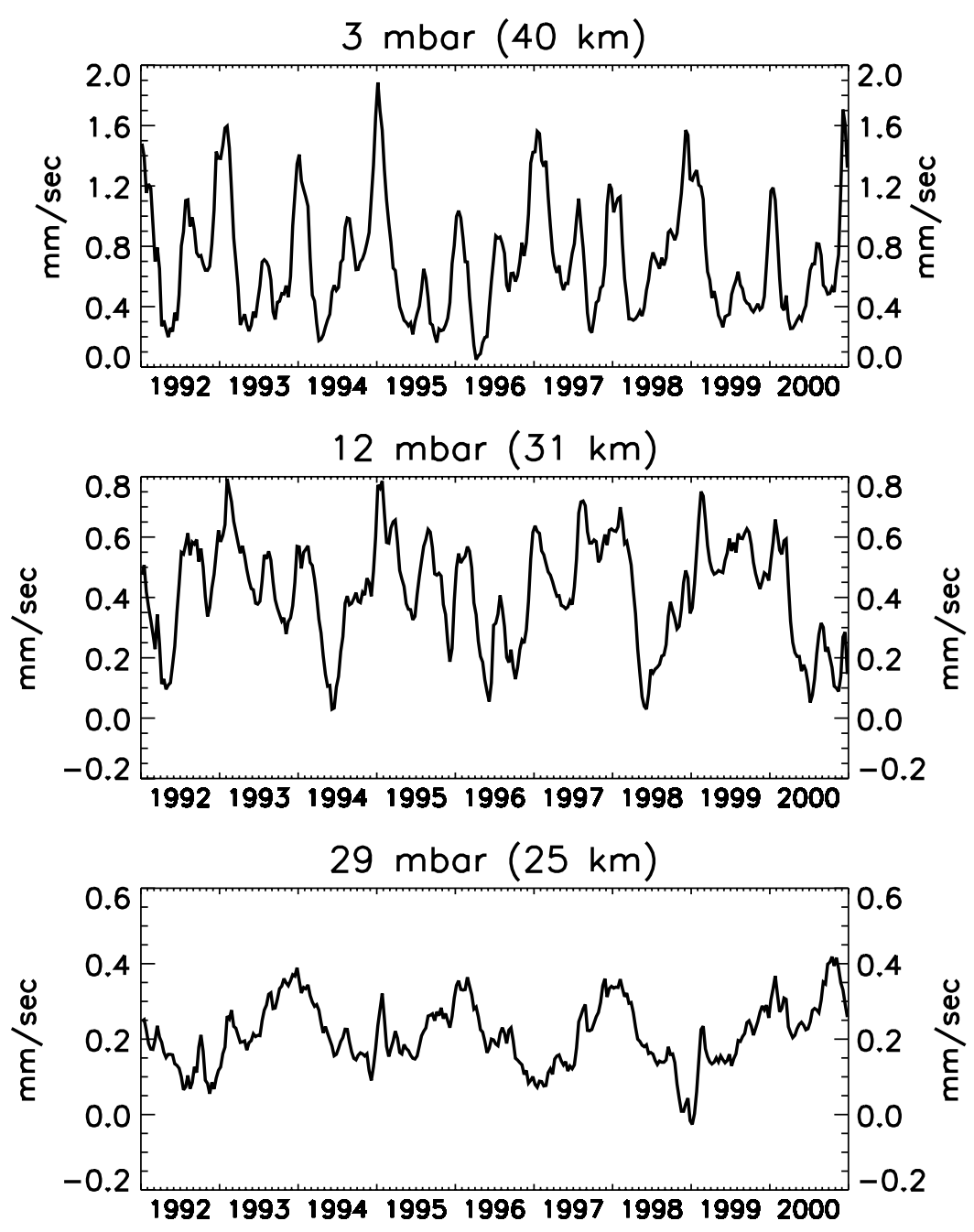

Figure 1. Time series of the equatorial residual mean vertical velocity $\left(\bar{w}^{*}\right)$ for model scenario A for the altitudes indicated.

UKMO meteorological data. We specifically examine the modeled QBO signatures in ozone and $\mathrm{CH}_{4}$ fields, and how these compare with UARS and TOMS data. This model evaluation is important as proper simulation of interannual variability is necessary to understand and assess long term ozone changes. We will also examine the relative roles of transport and temperature dependent photochemistry in controlling the tropical ozone changes in the lower and upper stratosphere.

\section{GSFC 2-D Model}

[11] The GSFC 2-D model has been described previously [Douglass et al., 1989; Jackman et al., 1990; Considine et al., 1994; Jackman et al., 1996]. Our current model has been updated to the latest Jet Propulsion Laboratory (JPL) 2000 recommendations for the gas phase reaction rates and photolysis cross sections [Sander et al., 2000]. The model climatological transport formulation is discussed in detail by Fleming et al. [1999]. Here we provide a brief overview of the analogous application to interannually varying meteorological conditions for the stratosphere based on the 3-D UKMO assimilated winds and temperatures for $1992-2000$.
As with previous model versions, the current transport for the mesosphere above $1 \mathrm{mbar}$ is climatological and is derived from the CIRA-86 zonal mean and planetary wave reference atmospheres [Fleming et al., 1990; Barnett and Labitzke, 1990].

[12] Following the methodology originally formulated by Garcia and Solomon [1983], a meridional stream function is calculated to obtain the transformed Eulerian mean circulation $\left(\bar{v}^{*}, \bar{w}^{*}\right)$. The stream function is derived from: (1) the zonal mean temperatures and zonal winds; (2) the vertical gradient of the mechanical forcing from planetary- and

Table 1. Description of Model Simulations

\begin{tabular}{cc}
\hline Scenario & Description \\
\hline A & temperature and all transport components varied interannually \\
B & scenario A + climatological $\mathrm{O}_{3}$ and $\mathrm{H}_{2} \mathrm{O}$ used in diabatic \\
& heating rates \\
C & scenario A + QBO temperature anomalies increased by $40 \%$ \\
D & interannual transport from scenario A + climatological \\
& temperatures used in reaction rates \\
E & climatological transport + interannual temperatures \\
& from scenario A used in reaction rates \\
F & scenario A + all odd nitrogen species kept constant \\
\hline
\end{tabular}



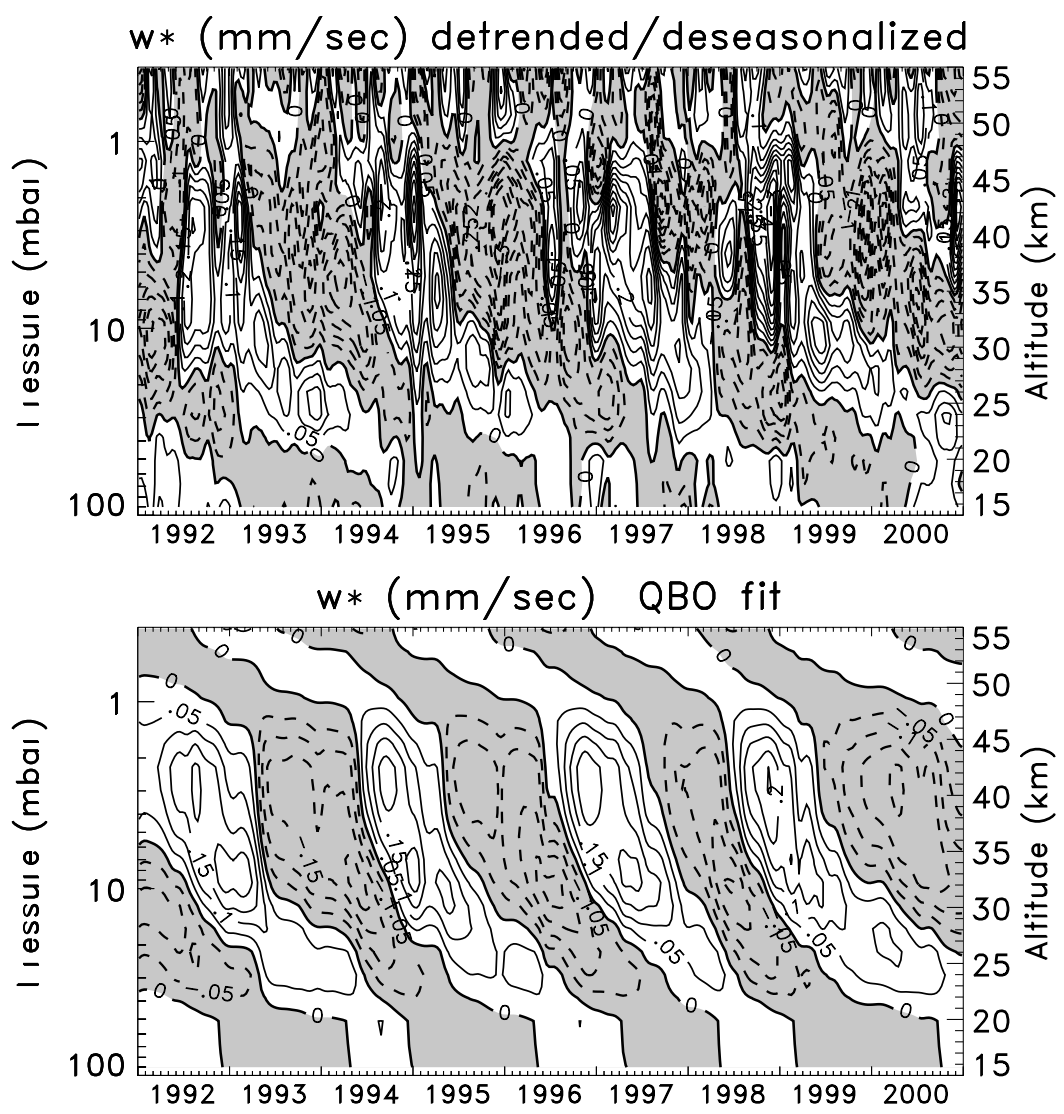

Figure 2. Equatorial time-height sections of the model residual mean vertical velocity $\left(\bar{w}^{*}\right)$ for model scenario A. Shown are the time series in which the trend and seasonal cycles have been removed by regression analysis and then smoothed by 2 passes of a 3-point running average (top), and the QBO statistical fit to the detrended and deseasonalized time series (bottom). Contour intervals are $0.05 \mathrm{~mm} / \mathrm{sec}$. Negative anomalies are shaded. See text for details of the QBO fitting procedure.

synoptic-scale waves, gravity waves, and equatorial Kelvin and Rossby-Gravity waves; and (3) the latitudinal gradient of the total heating rate which is comprised of diabatic, latent, and net eddy heating.

[13] The planetary- and synoptic-scale wave forcing are proportional to the Eliassen-Palm (E-P) flux divergence [e.g., Andrews et al., 1987] computed from the UKMO winds and temperatures. Momentum forcing from thermally damped equatorial Kelvin and Rossby-Gravity waves is computed using the parameterization discussed by Gray and Pyle, [1989]. Gravity wave forcing above $10 \mathrm{mbar}$ is computed from the parameterization of Lindzen [1981] and Holton and Zhu [1984], using the background zonal mean temperature and zonal wind fields to diagnose the monthly, latitudinal, and vertical distributions of gravity wave drag and diffusion based on a given set of fixed gravity wave parameters. The computed gravity wave drag and diffusion in the stratosphere will undergo interannual variations due to the varying background UKMO zonal wind field. However, since the background winds in the mesosphere are climatological, the resulting wave drag and diffusion computed above 1 mbar changes very little from year to year, with only a small interannual component due to the yearly changing background winds in the stratosphere.

[14] The diabatic heating rates are computed following Rosenfield et al. [1994], using the interannually varying
UKMO temperatures and HALOE ozone and water vapor. As discussed in the next section, we will show results using both climatological and interannually varying HALOE ozone and water vapor fields in the diabatic heating rate calculations. We do not account for the radiative effects of the anomalous stratospheric aerosol loading during 19911992 caused by the Mt. Pinatubo volcanic eruption. However, this should not strongly impact the QBO signals of concern in the present study. Latent heating rates for the troposphere are climatological and are based on the work by Newell et al. [1974]. Net gravity wave heating is computed following Schoeberl et al. [1983] and Huang and Smith [1991], utilizing the vertical diffusion rates computed from the gravity wave parameterization discussed above. Eddy heating from planetary- and synoptic-scale waves [e.g., Andrews et al., 1987] is computed from the UKMO 3-D meteorological fields.

[15] Following Randel and Garcia [1994], latitudinal eddy diffusion $\left(K_{y y}\right)$ due to planetary- and synoptic-scale wave dissipation is computed self-consistently with the circulation and is taken as the ratio of the E-P flux divergence to the latitudinal gradient of zonal mean potential vorticity. The model vertical eddy diffusion $\left(K_{z z}\right)$ in the troposphere and lower stratosphere below 10 mbar is derived from the Brunt-Väisälä frequency squared as computed from the UKMO temperatures. $K_{z z}$ in the mesosphere 

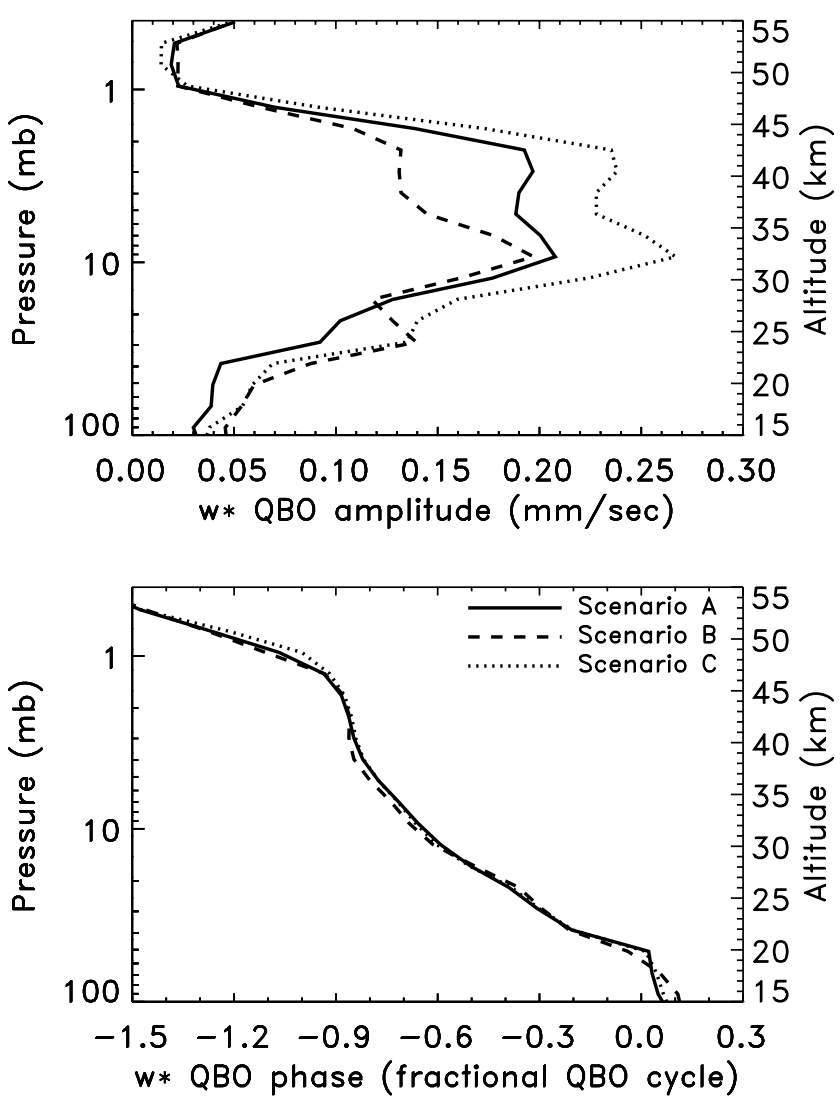

Figure 3. Equatorial vertical profiles of the QBO amplitude and phase of the residual mean vertical velocity $\left(\bar{w}^{*}\right)$ from model scenarios A (solid line), B (dashed line), and $\mathrm{C}$ (dotted line). See text for details concerning the QBO statistical fitting.

and upper stratosphere above 10 mbar is obtained from the gravity wave parameterization discussed above.

\section{Tropical Dynamical Variability}

[16] Randel et al. [1999] previously presented a detailed analysis of the zonal mean interannual and QBO dynamical features derived on a global basis from the UKMO data. In this section, we present a brief overview of the interannual dynamical variability in the tropical stratosphere derived from the UKMO data for use in our 2-D model.

[17] To examine the relative impact on the model constituents of interannual variations in the advective circulation and eddy diffusion fields, we ran a simulation in which $K_{z z}$ was set to climatology with the circulation and $K_{y y}$ fields varied interannually. We also ran an analogous simulation in which the $K_{y y}$ field was set to climatology with the circulation and $K_{z z}$ fields varied interannually. We found that interannual changes in $\mathrm{K}_{z z}$ have a negligible effect on the model constituent simulations in the tropical stratosphere. Interannual changes in $K_{y y}$ have a relatively small impact on the model $\mathrm{CH}_{4}$ distribution, but have virtually no effect on the profile and total ozone simulations. Therefore in this study, we will focus on the interannual variations in the vertical velocity field of the residual circulation $\left(\bar{w}^{*}\right)$ which control the zonal mean constituent distributions in the tropics. In our diagnostic model formulation, the diabatic heating rates dominate the forcing of $\bar{w}^{*}$ in the equatorial stratosphere. The momentum forcing from tropical Kelvin and Rossby-Gravity waves and extratropical planetary waves has a much smaller impact on the model circulation and constituent simulations. In the following sections, we will discuss the sensitivity of the model results to different heating rate calculations.

[18] Figure 1 shows equatorial time series of our computed $\bar{w}^{*}$ for $1992-2000$ at three stratospheric levels. Here we show $\bar{w}^{*}$ obtained using a heating rate calculation in which the temperature, ozone, and water vapor fields all change interannually. This is designated scenario A as listed in Table 1. Well-known features are illustrated in Figure 1, such as the strong QBO signature in lower stratosphere and the dominant SAO in the upper stratosphere, with a transition between the two regimes in the middle stratosphere. The upper stratospheric time series at 3 mbar also shows typically stronger upwelling during the $\mathrm{NH}$ winter compared to the $\mathrm{SH}$ winter. This is consistent with the stronger dynamical forcing during $\mathrm{NH}$ winter, which also produces stronger tropical easterlies [e.g., Garcia et al., 1997]. Figure 1 also reveals a strong interannual component at all levels, and it appears that the QBO modulates the SAO circulation in the upper stratosphere. This is more clearly seen in the time-height section in Figure 2 (top) in which the trend and seasonal cycles in the $\bar{w}^{*}$ time series have been removed by regression analysis. Maximum anomaly amplitudes are on the order of $\pm 0.5 \mathrm{~mm} \mathrm{~s}^{-1}$, with a characteristic downward propagation feature evident.

[19] To isolate the QBO signal in the $\bar{w}^{*}$ anomaly field, we follow the methodology outlined previously [Wallace et al., 1993; Randel and Wu, 1996; Randel et al., 1999]. The interannual anomalies are fit with a linear regression containing the two leading empirical orthogonal functions (EOFs) of the zonal wind QBO reference time series. This time series is derived from optimal linear combinations of near-equatorial radiosonde observations of zonal wind for 70-10 mbar. Together, these two leading EOFs explain more than $90 \%$ of the QBO zonal wind variance for 19561990 [Wallace et al., 1993; Randel et al., 1999]. This technique therefore isolates time variations in $\bar{w}^{*}$ (or other parameters) throughout the stratosphere that are coherent with the lower stratospheric zonal wind QBO. Figure 2 (bottom) shows the resulting QBO fit of $\bar{w}^{*}$, which captures a significant amount of the interannual variability in $\bar{w}^{*}$. An out-of-phase relationship between the upper and lower stratosphere is also evident.

[20] The equivalent harmonic amplitude and phase of the QBO signal in $\bar{w}^{*}$ from scenario A are shown in Figure 3 (solid lines). These are computed from the two leading EOFs shown in Figure 2 (bottom), in a similar fashion to the methodology outlined by Wallace et al. [1993]. The QBO amplitude maximizes at $\sim 0.2 \mathrm{~mm} \mathrm{~s}^{-1}$ in the middle and upper stratosphere between 32 and $42 \mathrm{~km}$. There is a sharp drop-off in amplitude above and below this layer. The phase plot in Figure 3 (plotted in fractional QBO cycle) shows the characteristic downward propagation, with a near $180^{\circ}$ phase shift ( 0.5 cycle) between 3 and 30 mbar.

[21] Our results in Figure 2 are similar to the radiatively determined $\bar{w}^{*}$ of Randel et al. [1999], with a strong 

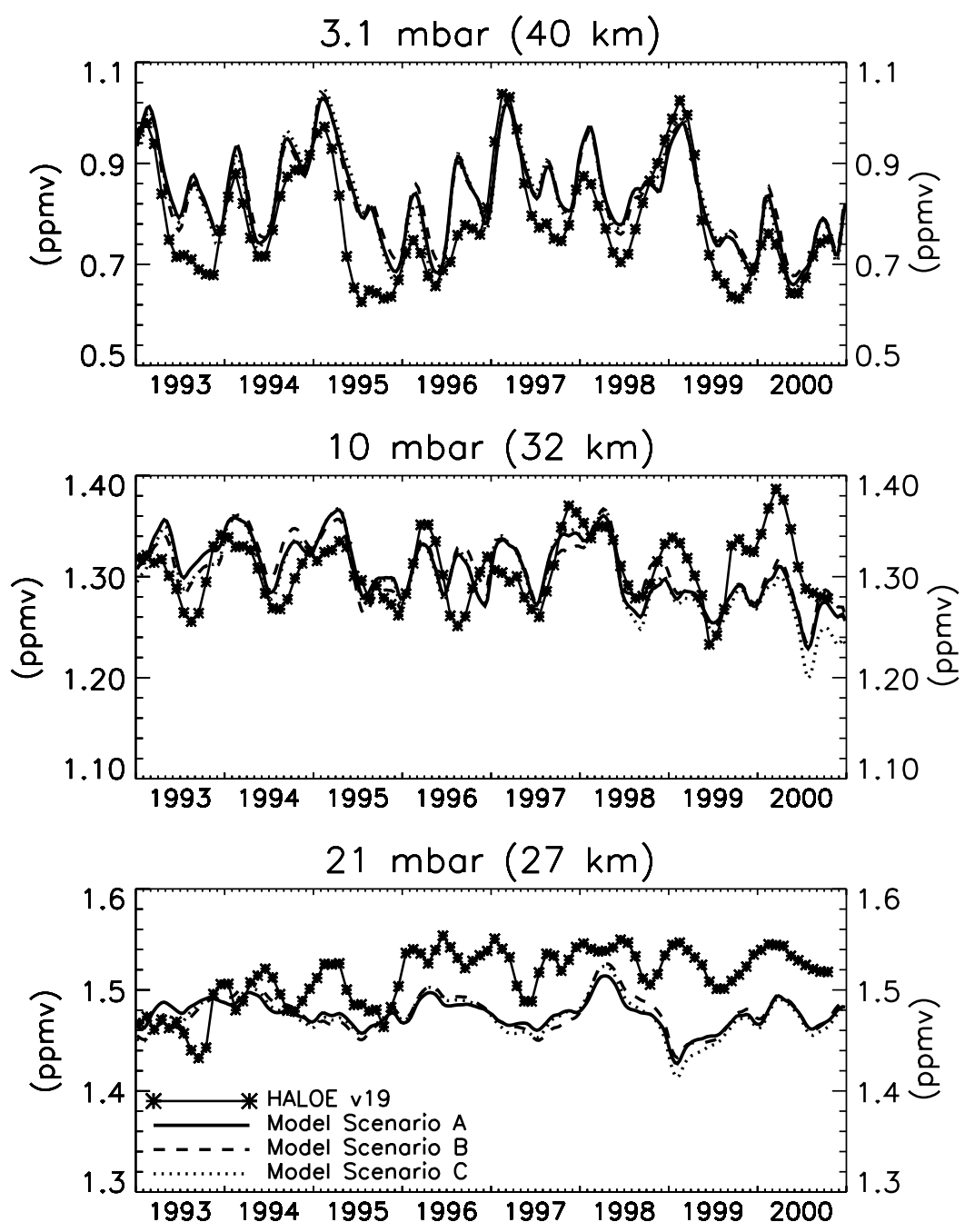

Figure 4. Time series of $\mathrm{CH}_{4}$ from UARS HALOE version 19 data (light solid line-asterisk), and model scenarios A (heavy solid line), B (dashed line), and $\mathrm{C}$ (dotted line) for $10^{\circ} \mathrm{S}-10^{\circ} \mathrm{N}$ at the altitudes indicated.

correlation between the $\bar{w}^{*}$ field, the temperature variations, and the net diabatic heating rates in the tropical stratosphere. We find that our computed $\bar{w}^{*}$ anomalies are anticorrelated with and slightly precede, by $1-2$ months, our 2-D model ozone (section 4.2) and UKMO temperature anomalies at 20-40 mbar. Our $\bar{w}^{*}$ results therefore appear to be grossly consistent with the lower stratospheric vertical velocities inferred from the ascent rates of HALOE equatorial $2 \mathrm{CH}_{4}+$ $\mathrm{H}_{2} \mathrm{O}$ [Niwano and Shiotani, 2001]. These authors report that the positive $\mathrm{QBO}$ variations in ascent rates precede the negative anomalies in temperature and ozone by $2-3$ months at 30-60 mbar. However, they suggest that the QBO variation in their derived ascent rates may be larger than that determined from radiative calculations.

[22] Figure 3 shows our model results from two additional heating rate calculations. Scenario B (dashed line) uses the interannually changing UKMO temperatures, but with climatological (1993-2000 average) distributions of ozone and water vapor from HALOE. The resulting $\bar{w}^{*} \mathrm{QBO}$ signal is consistent with previous findings [e.g., Dunkerton, 1997; Randel et al., 1999]. Using climatological $\mathrm{O}_{3}$ and $\mathrm{H}_{2} \mathrm{O}$ in the heating rates enhances the $\bar{w}^{*} \mathrm{QBO}$ amplitude in the lower stratosphere below $28 \mathrm{~km}$, and decreases the amplitude above $28 \mathrm{~km}$, especially at $35-43 \mathrm{~km}$. Scenario B also results in a secondary maximum near $24 \mathrm{~km}$. The difference in the heating and $\bar{w}^{*}$ calculations between scenarios $\mathrm{A}$ and $\mathrm{B}$ is primarily due to the variations in ozone heating. In the lower stratosphere where the temperature and ozone changes are in phase, the net heating due to the QBO ozone anomalies tend to cancel the effect of the QBO-induced circulation, that is, downward motion (relative to the mean) gives positive ozone anomalies and enhanced ozone heating thereby reducing the intensity of the downward motion. In the upper stratosphere where temperature and ozone are out of phase, their effects on the net heating and $\bar{w}^{*}$ are in phase, that is, relative downward motion gives positive temperature anomalies and negative ozone anomalies (via the temperature-dependent reaction rates) which decreases the heating and enhances the downward motion. The radiative effects of interannual changes in ozone therefore decrease the interannual and QBO variations in $\bar{w}^{*}$ below $\sim 28 \mathrm{~km}$ and enhance the variations above $\sim 28 \mathrm{~km}$. However, since the QBO anomalies in temperature and ozone are, for the most part, either in phase or out of phase in the stratosphere, the 


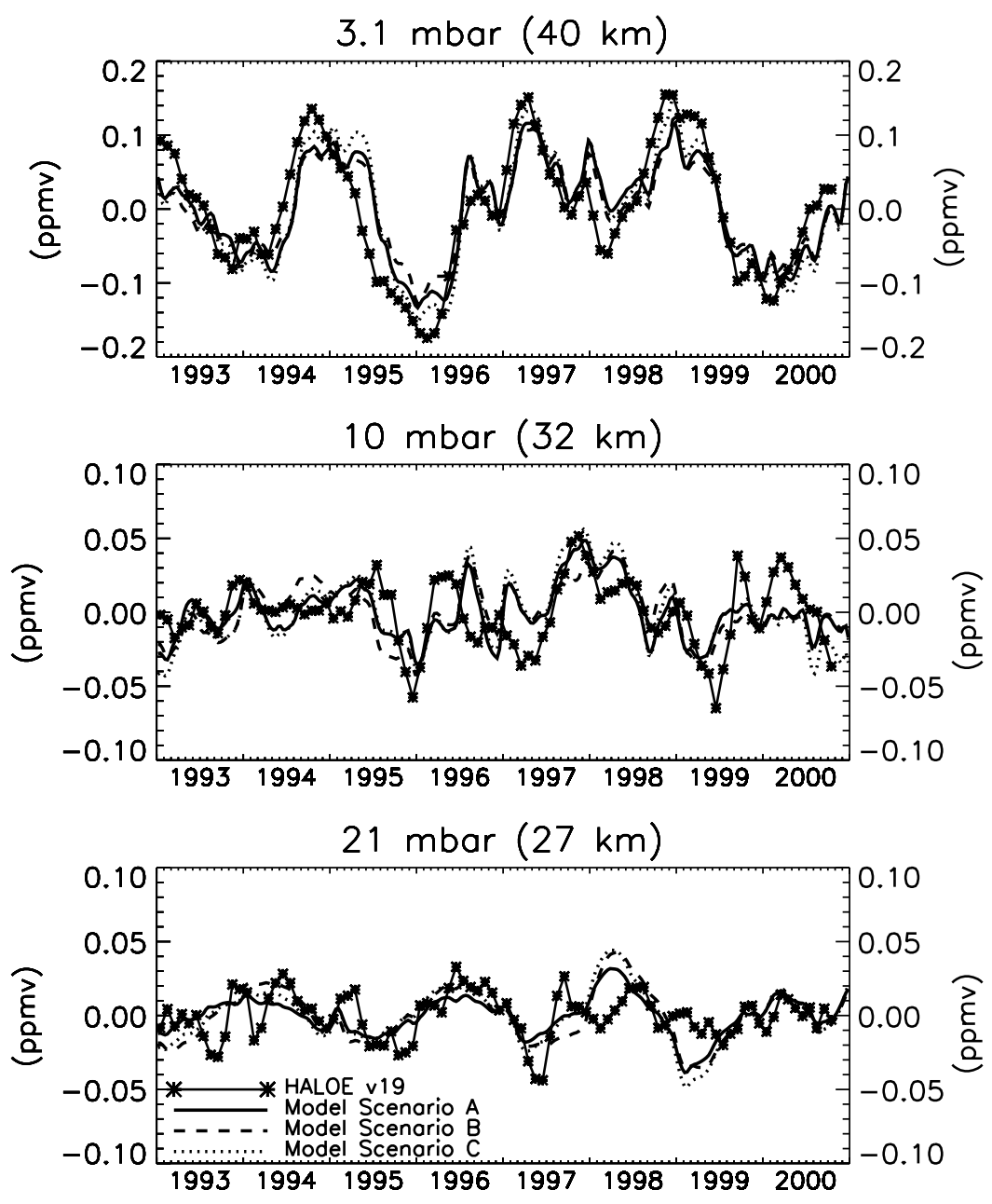

Figure 5. Time series of detrended and deseasonalized $\mathrm{CH}_{4}$ from UARS HALOE version 19 data (light solid line-asterisk), and model scenarios A (heavy solid line), B (dashed line), and C (dotted line) for $10^{\circ} \mathrm{S}-10^{\circ} \mathrm{N}$ at the altitudes indicated. The trend and seasonal cycles have been removed by regression analysis. A solar cycle component has also been removed from the HALOE data.

phase of the QBO in $\bar{w}^{*}$ in Figure 3 changes very little between scenarios $\mathrm{A}$ and $\mathrm{B}$.

[23] Comparisons with Singapore rawinsonde data suggest that the UKMO temperatures underestimate the QBO amplitude by at least 40\% [Randel et al., 1999]. This would result in an underestimation of the QBO amplitude in the computed radiative heating rates and $\bar{w}^{*}$ in the equatorial stratosphere. Randel et al. [1999] found that increasing the QBO temperature anomalies in the UKMO data by $40 \%$ substantially increased the corresponding amplitude in their derived $\bar{w}^{*}$ in the lower stratosphere, with a smaller effect in the upper stratosphere. To understand how such a bias might affect our model constituent simulations, we made a similar heating rate and $\bar{w}^{*}$ calculation in which the QBO amplitude in the UKMO temperatures was increased by $40 \%$ (scenario C). The $\mathrm{O}_{3}$ and $\mathrm{H}_{2} \mathrm{O}$ in this scenario were varied interannually as in scenario A. The resulting QBO amplitude in $\bar{w}^{*}$ (Figure 3, dotted line) is enhanced significantly throughout most of the equatorial stratosphere compared to scenario A (solid line). The QBO phase in $\bar{w}^{*}$ exhibits only negligible changes between scenarios $\mathrm{A}$ and $\mathrm{C}$ in Figure 3. In the following sections, we will discuss how the different heating rate and $\bar{w}^{*}$ calculations in scenarios $\mathrm{A}, \mathrm{B}$, and $\mathrm{C}$ affect the model simulated interannual constituent variations.

\section{Model Constituent Simulations}

[24] We now compare the model simulated interannual changes in equatorial $\mathrm{CH}_{4}$ and ozone with UARS and TOMS observations. We will show results from scenarios $\mathrm{A}, \mathrm{B}$, and $\mathrm{C}$ described in section 3 . We will also discuss the relative influence of interannual changes in transport, temperature, and odd nitrogen photochemistry on the resulting ozone simulations.

[25] All results are taken from simulations in which the model was run for 41 years using 1960-2000 time-dependent source gas boundary conditions from WMO [1999]. For years corresponding to $1960-1992$, the simulations use the 1992 UKMO-derived transport fields (the first full year of the UKMO analyses) repeated each year, with the UKMOderived transport for each particular year then used for 1993-2000. We note that long term variability introduced by the 11-year cycle in solar UV flux was not included in the model simulations. 

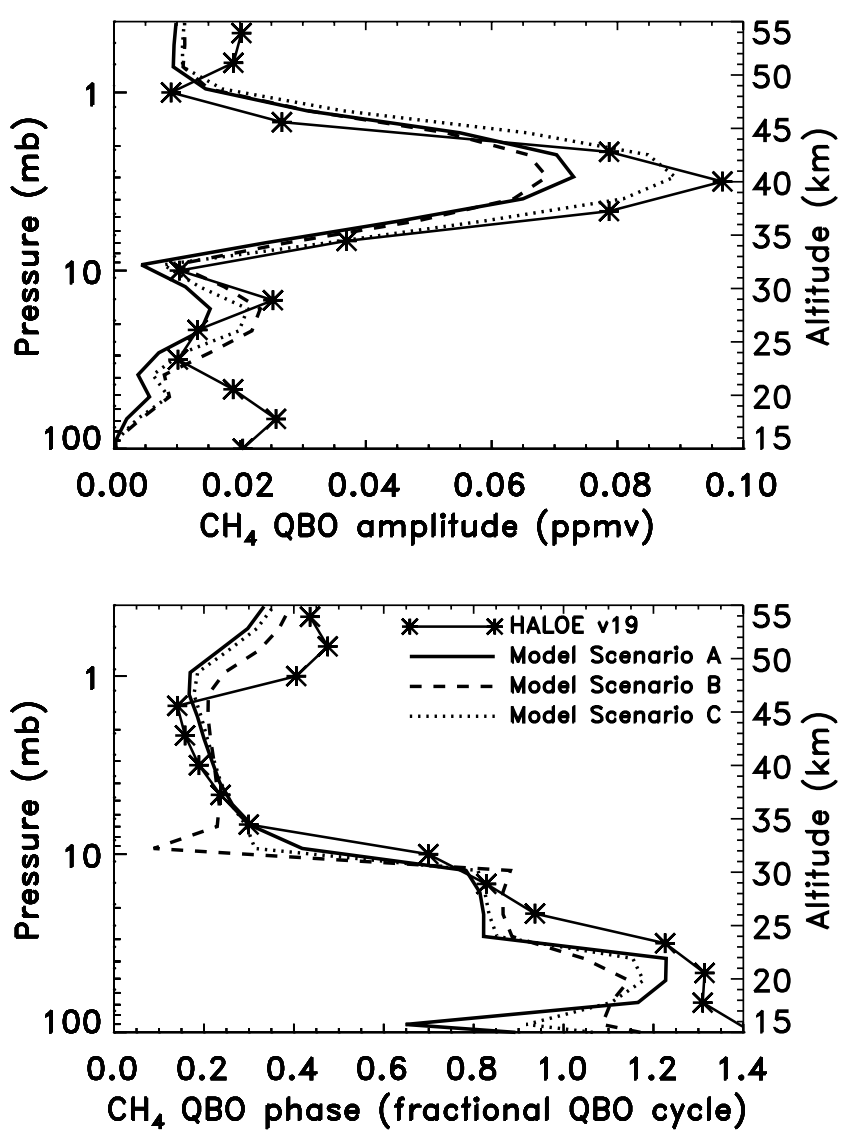

Figure 6. Vertical profiles of the $\mathrm{QBO}$ amplitude and phase of $\mathrm{CH}_{4}$ from HALOE version 19 (light solid lineasterisk), and model scenarios A (heavy solid line), B (dashed line), and $\mathrm{C}$ (dotted line) for $10^{\circ} \mathrm{S}-10^{\circ} \mathrm{N}$. See text for details concerning the QBO statistical fitting.

[26] Because we use the 1992 dynamics for all years prior to 1992 instead of the actual yearly dynamics which are not available, it is important to estimate the possible bias introduced by the model's "memory" of the initial conditions. To do this we ran a simulation using the 1993 dynamics repeated each year for 1960-1993, with the proper yearly dynamics then used for 1994-2000. We also ran an analogous simulation using the 1994 dynamics. We found that the model in the tropics has a spin-up time of about 1 year; that is, it takes 1 year for the model to adjust to different initial conditions caused by the different dynamical fields. Therefore in the following sections, we omit the 1992 results and show only the constituent simulations for 1993-2000. This also avoids the problems with UARS data contamination and other complicating factors caused by the anomalous Pinatubo aerosol loading during 1991-1992.

\section{1. $\mathrm{Ch}_{4}$}

[27] Figure 4 compares time series of equatorial $\left(10^{\circ} \mathrm{S}-\right.$ $\left.10^{\circ} \mathrm{N}\right)$ HALOE v19 monthly mean $\mathrm{CH}_{4}$ along with the model simulations at three stratospheric levels. The model results from the three heating rate calculations (scenarios A, $\mathrm{B}$, and C) show only small differences, and these will be discussed below. The HALOE data show generally weak seasonal and interannual cycles in the lower stratosphere. The amplitudes of these variations increase with altitude, coincident with the increase in the vertical gradient of methane [e.g., Cordero et al., 1997]. The model simulations qualitatively mimic this altitude variation, and are able to match the phase of the seasonal cycles in the HALOE data quite well in the middle and upper stratosphere. The modeldata agreement in the absolute value of $\mathrm{CH}_{4}$ is especially good in the middle and upper stratosphere throughout the time period. The simulations at 21 mbar reveal a small underestimation of about $0.05 \mathrm{ppmv}$ in the absolute amount of $\mathrm{CH}_{4}$ after 1995. This deficiency is likely due to a model underestimation of the mean tropical upwelling in the lower stratosphere, resulting in too little $\mathrm{CH}_{4}$ transported up from the troposphere.

[28] The interannual changes in the model and HALOE $\mathrm{CH}_{4}$ are more clearly seen in Figure 5, which shows the time series with the trend and seasonal cycles removed by statistical regression analysis [e.g., WMO, 1999] (a solar cycle component has also been removed from the HALOE data). Such interannual variations have previously been investigated in the UARS long-lived tracer data [Cordero et al., 1997; O'Sullivan and Dunkerton, 1997; Randel et al., 1998; Dunkerton, 2001]. The models track the QBO-type changes in the data reasonably well throughout the time period, including the phase of the QBO variation in the lower and upper stratosphere. Although some of the shorterterm oscillations seen in the data are not as well resolved in the model at 10 and 21 mbar.

[29] Vertical profiles of the amplitude and phase of the methane QBO signal are shown in Figure 6. These were computed following the same methodology used for the $\bar{w}^{*}$ field (Figure 3) as discussed in section 3. The models capture the general altitudinal variation of the HALOE amplitude, with a sharp upper stratospheric maximum centered at 3 mbar $(40 \mathrm{~km})$ coincident with the strongest vertical gradient in $\mathrm{CH}_{4}$, a minimum near 10 mbar, and secondary maximum near 20 mbar. All three models are similar in phase (Figure 6, bottom panel), and resolve fairly well the altitudinal phase variation of the observations. There is some model discrepancy in phase at the very lower and upper levels where the amplitudes are quite weak.

[30] Although there are only small changes in the absolute value of $\mathrm{CH}_{4}$ among the three scenarios in Figure 4, the changes in the QBO amplitude are more significant. Figures 5 and 6 show that model scenario A (heavy solid line) tends to underestimate the QBO amplitude at most heights, with a difference of $25-30 \%$ at $40 \mathrm{~km}$. Including climatological $\mathrm{O}_{3}$ and $\mathrm{H}_{2} \mathrm{O}$ in the heating rates (scenario $\mathrm{B}$, dashed line) affects the $\mathrm{CH}_{4}$ amplitude in a manner consistent with the $\bar{w}^{*}$ field (Figure 3); that is, the amplitude increases in the lower stratosphere below $35 \mathrm{~km}$, and decreases in the upper stratosphere at $38-43 \mathrm{~km}$, although the $\mathrm{CH}_{4}$ amplitude decrease near $40 \mathrm{~km}$ appears to be smaller than the relative decrease in $\bar{w}^{*}$ seen in Figure 3. Scenario B is closer to the HALOE amplitude between 10 and 20 mbar, but scenario A compares slightly better at $40 \mathrm{~km}$. As expected, increasing the QBO temperature anomalies in the heating rates (scenario $\mathrm{C}$, dotted line) increases the $\mathrm{QBO} \mathrm{CH}_{4}$ amplitude throughout the stratosphere to be closer to the HALOE data. The improvement is especially noticeable in the region of the $40 \mathrm{~km}$ maximum. Among the three models, scenario C 


\section{$3.1 \mathrm{mbar}(40 \mathrm{~km})$}
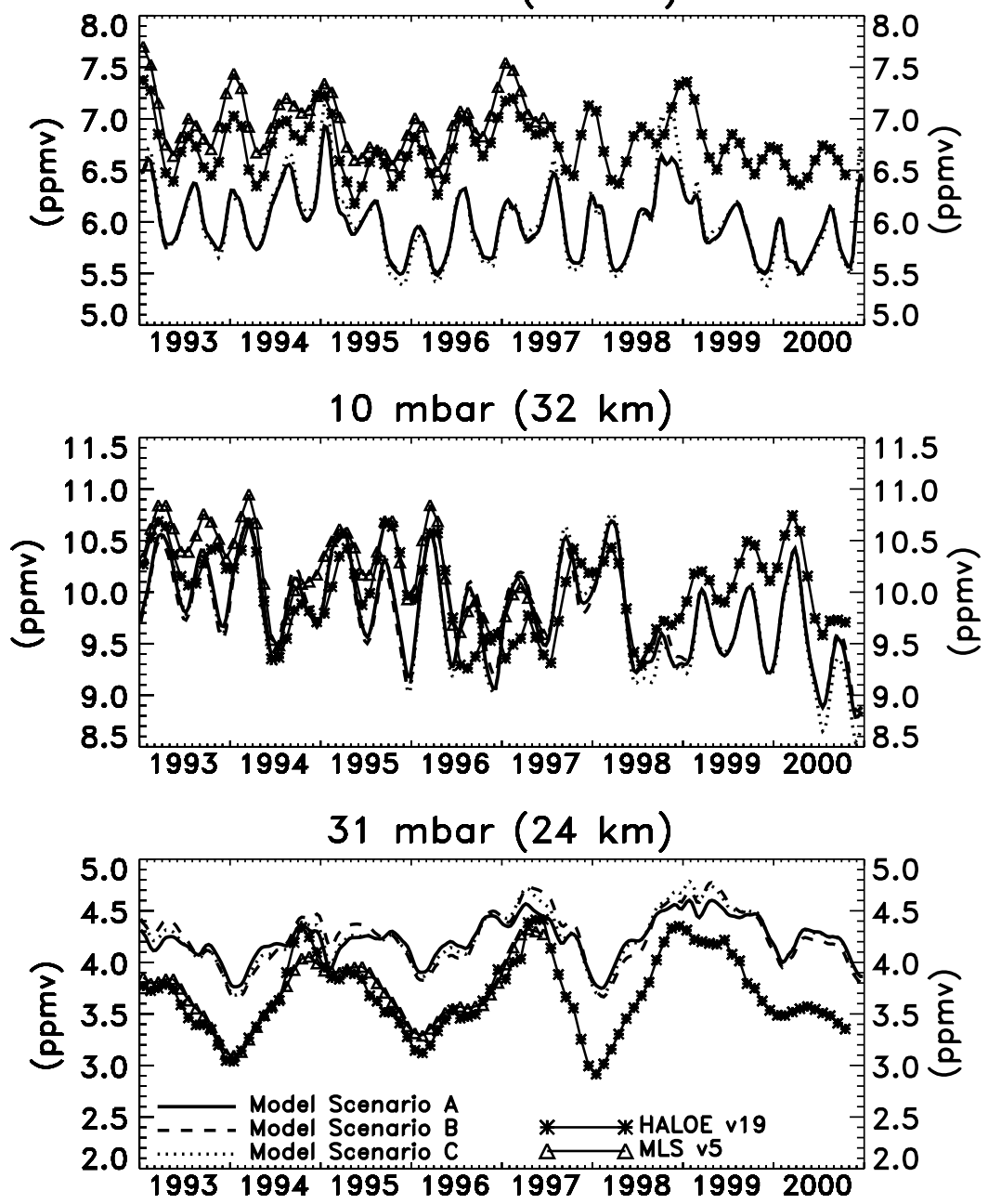

Figure 7. Time series of $\mathrm{O}_{3}$ from UARS HALOE version 19 data (light solid line-asterisk), MLS version 5 data (light solid line-triangles), and model scenarios A (heavy solid line), B (dashed line), and C (dotted line) for $10^{\circ} \mathrm{S}-10^{\circ} \mathrm{N}$ at the altitudes indicated.

appears to provide the best overall agreement with the HALOE $\mathrm{CH}_{4}$ data in Figure 6.

[31] We note finally that the QBO response will be similar for other long-lived tracers with similar vertical gradients [Cordero et al., 1997]. For example, as with $\mathrm{CH}_{4}$, the vertical gradient in HF is weak in the lower stratosphere and strong in the upper stratosphere. The model and HALOE QBO responses in HF (not shown) are weak in the lower stratosphere and have sharp maxima in the upper stratosphere near $40 \mathrm{~km}$, but are $180^{\circ}$ out of phase with the QBO responses in $\mathrm{CH}_{4}$ due to the reversed orientation of the vertical gradients of the two constituents.

\subsection{Profile Ozone}

[32] Figure 7 shows time series for 1993-2000 of ozone from the UARS Microwave Limb Sounder (MLS) v5 and HALOE v19 and the model simulations at three stratospheric levels. The time series with the trend and seasonal cycles removed via regression analysis are shown in Figure 8 (again, a solar cycle component has also been removed from the HALOE and MLS data). Note the MLS data is only available through June 1997. Unlike $\mathrm{CH}_{4}$, there is a sharp vertical gradient in ozone in the lower stratosphere below the ozone peak, resulting in a strong transport-induced QBO signal [e.g., Cordero et al., 1997]. The ozone variations transition to a dominant SAO in the middle and upper stratosphere in both the model and data. The model tracks the phase of the seasonal and interannual signals in the UARS data fairly well. A strong QBO-type feature is seen at all levels of the stratosphere in the HALOE and MLS data, and the model agrees qualitatively with these observations. As with methane, the differences in the absolute concentration of ozone among the three model scenarios are relatively small (Figure 7), with more significant differences in the QBO anomaly amplitude (Figures 8 and 10). This will be discussed below.

[33] The model simulations in Figure 7 systematically overestimate the observations by $0.55 \mathrm{ppmv}$ in the lower stratosphere where ozone is controlled by transport. Since the MLS and HALOE data agree quite well, we suspect that this bias is caused by the model underestimating the mean upwelling in the tropics causing higher ozone concentrations than observed. This is consistent with Figure 4 in which overly weak model upwelling caused an underesti- 

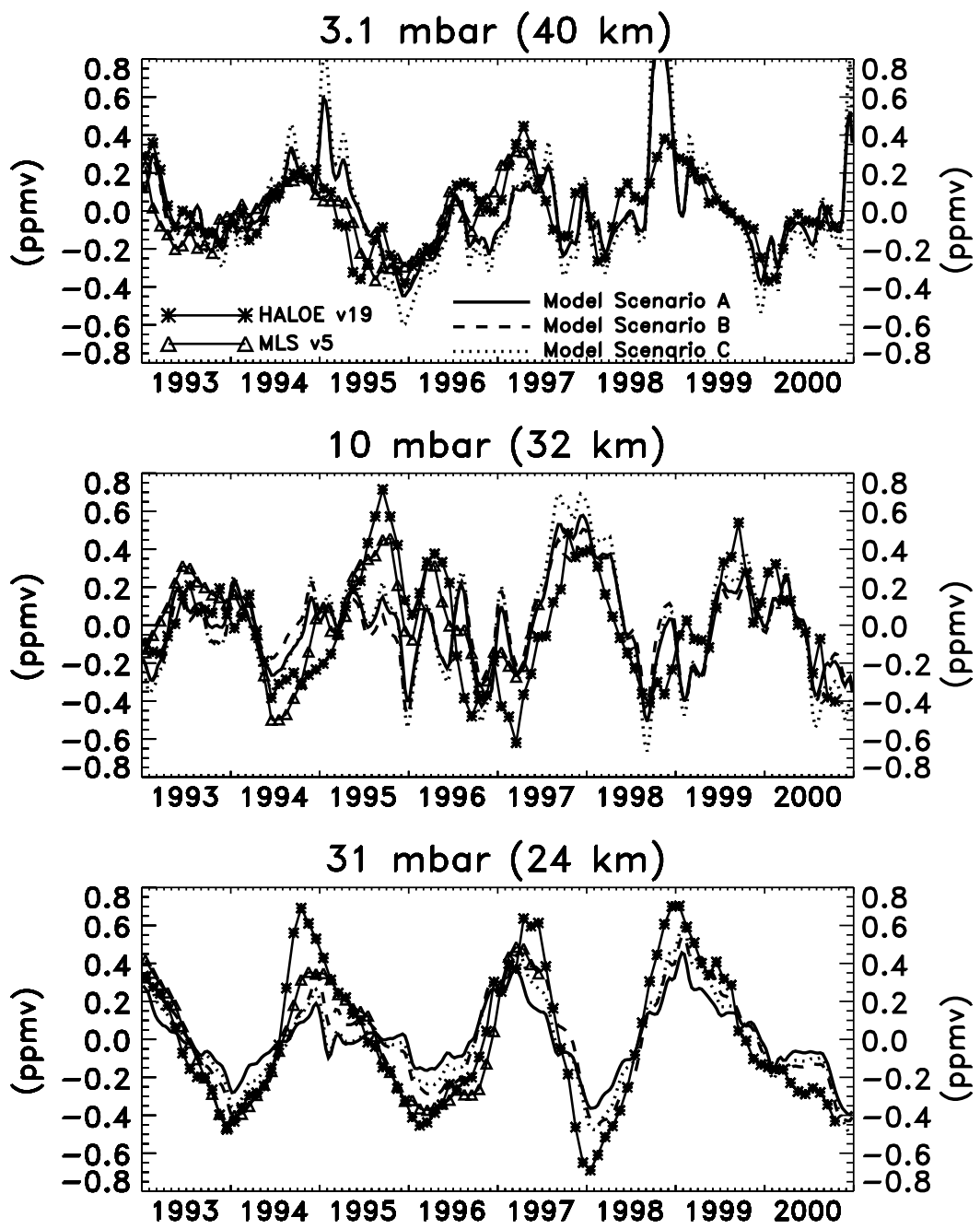

Figure 8. Time series of detrended and deseasonalized $\mathrm{O}_{3}$ from UARS HALOE version 19 data (light solid line-asterisk), MLS version 5 data (light solid line-triangles), and model scenarios A (heavy solid line), $\mathrm{B}$ (dashed line), and $\mathrm{C}$ (dotted line) for $10^{\circ} \mathrm{S}-10^{\circ} \mathrm{N}$ at the altitudes indicated. The trend and seasonal cycles have been removed by regression analysis. A solar cycle component has also been removed from the HALOE and MLS data.

mation of $\mathrm{CH}_{4}$ relative to the data. As ozone becomes increasingly less influenced by transport with increasing altitude, this bias becomes very small in the middle stratosphere. The model underestimation of the data in the upper stratosphere in Figure 7 is due to the well-known ozone deficit problem [e.g., Minschwaner et al., 1993; Eluszkiewicz and Allen, 1993; Dessler et al., 1996] as discussed in our previous work [Jackman et al., 1996]. This deficiency has been reduced somewhat in the present model simulations that include the reaction $\mathrm{ClO}+\mathrm{OH} \rightarrow \mathrm{HCl}+\mathrm{O}_{2}$ [Sander et al., 2000]. The current model scenarios systematically underpredict the $\mathrm{HALOE}_{3}$ by 0.75 ppmv $(11 \%)$ at 3 mbar.

[34] Equatorial time-height sections of the QBO fits to the detrended and deseasonalized ozone time series from UARS and model scenario A are shown in Figure 9. The QBO signal explains a significant amount of the interannual variability in both the model and data. For the most part, the model shows good qualitative consistency with the data, revealing a maximum QBO signal in the lower stratosphere near $25 \mathrm{~km}$, and a separate maximum in the upper stratosphere near $35 \mathrm{~km}$.

[35] The corresponding amplitudes and phases of the QBO fits for the UARS data and model scenarios A, B, and $\mathrm{C}$ are shown in Figure 10. As with the $\mathrm{CH}_{4}$ comparisons, the models capture quite well the altitudinal phase change below $45 \mathrm{~km}$ where the QBO amplitude is significant. Model scenario A (heavy solid line) shows some general consistency with the data in the amplitude variation with altitude, that is, maxima near 25 and $35 \mathrm{~km}$, with a minimum in between. However, below $40 \mathrm{~km}$, the magnitude of the QBO amplitude is systematically underestimated in the model by as much as a factor of 2 . Consistent with $\bar{w}^{*}$, the ozone QBO amplitude in scenario B (dashed line in Figures 7, 8, and 10) is enhanced (diminished) below (above) $28 \mathrm{~km}$ compared to scenario A. However, the differences between the two heating rate calculations become much less apparent above $35 \mathrm{~km}$ as ozone becomes increasingly controlled by photochemistry. The model QBO ozone amplitude in scenario $\mathrm{C}$ (in which the QBO temper- 

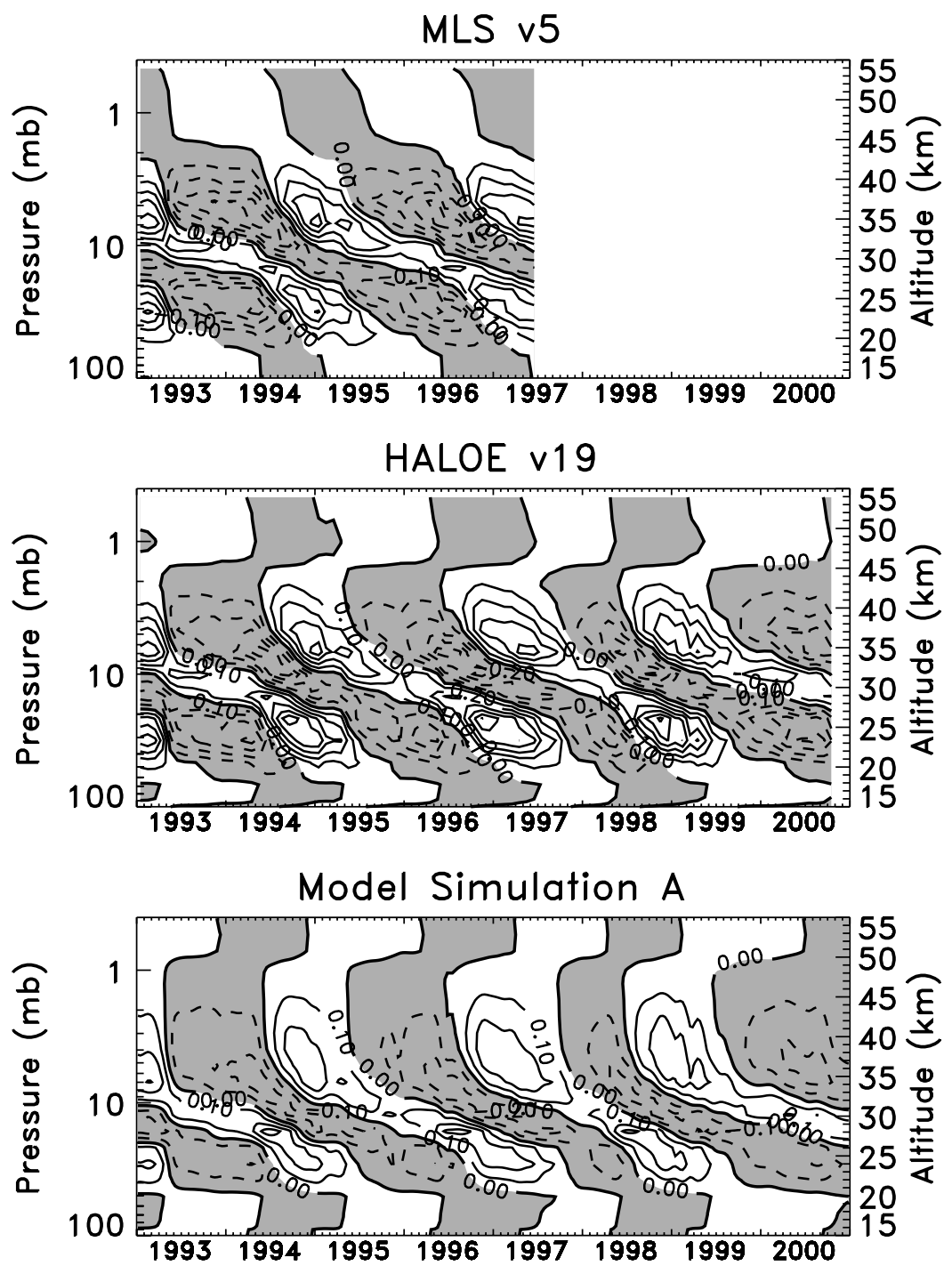

Figure 9. Equatorial time-height sections of the QBO statistical fit to the detrended and deseasonalized $\mathrm{O}_{3}$ time series for $10^{\circ} \mathrm{S}-10^{\circ} \mathrm{N}$. Shown are the MLS version 5 data (top), HALOE version 19 data (middle), and model scenario A (bottom). The contour interval is $0.1 \mathrm{ppmv}$ and negative anomalies are shaded. See text for details of the QBO fitting procedure.

ature anomalies have been increased by $40 \%$ ) is generally closer to the HALOE data than scenario A, but still underestimates the observed amplitude at most altitudes. The change in the modeled ozone in the lower stratosphere in scenario $\mathrm{C}$ is primarily due to the vertical velocity enhancements, with the upper stratospheric model ozone changes due mainly via the temperature dependent reaction rates.

[36] To further investigate the processes controlling the interannual ozone variations, we ran two additional model simulations listed in Table 1 . In scenario $\mathrm{D}$, the transport was allowed to vary interannually as in scenario A, but the temperatures in the photochemistry were set to climatological values. The opposite case (climatological transport, interannual temperatures in the photochemistry) was done in scenario E. The resulting detrended and deseasonalized $\mathrm{O}_{3}$ time series are shown in Figure 11, and the corresponding QBO amplitude and phase are shown in Figure 12. Transport almost completely determines the total interannual signal below $30 \mathrm{mbar}$, as scenario D (light solid line) is nearly identical to scenario A (heavy solid line). Scenario E (dashed line), which has only the interannual temperature dependent photochemistry with transport being climatological, exhibits very small interannual variability below 30 mbar. Transport and photochemistry have similar contributions to the ozone variability in the middle stratosphere, with photochemistry becoming dominant in the upper stratosphere above about 4 mbar.

[37] Below about 20 mbar, the transport-induced interannual signal is out of phase with the temperature effect, as downward motion (relative to the mean) in the lower stratosphere increases ozone directly, but also creates warmer temperatures which decreases ozone photochemically. This is seen in the time series at $31 \mathrm{mbar}$ in Figure 11 (bottom panel), and by the fact the QBO signal in scenario $\mathrm{E}$ is one-half cycle out of phase with scenarios A and D in the lower stratosphere (Figure 12, bottom panel). This is also 

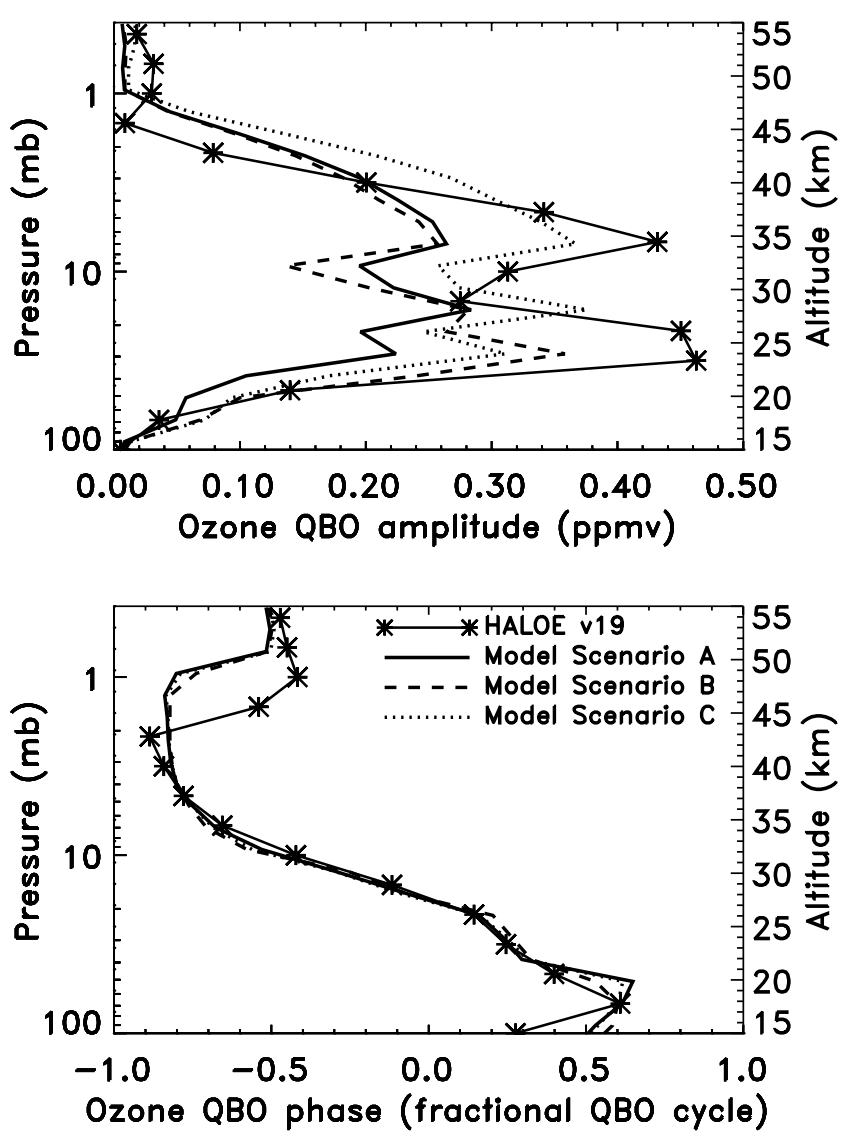

Figure 10. Vertical profiles of the QBO amplitude and phase of $\mathrm{O}_{3}$ from HALOE version 19 (light solid lineasterisk), and model scenarios A (heavy solid line), B (dashed line), and $\mathrm{C}$ (dotted line) for $10^{\circ} \mathrm{S}-10^{\circ} \mathrm{N}$. The amplitudes and phases are determined from the QBO statistical fitted time series shown in Figure 9. See text for details concerning the QBO statistical fitting.

illustrated by the fact that the QBO amplitude in scenario D somewhat exceeds that of the full interannual simulation (scenario A) in the lower stratosphere (Figure 12, top panel). This out-of-phase relationship diminishes with height as the temperature impact on ozone reinforces that of transport above about 10 mbar.

[38] Previous modeling studies have investigated the importance of transport-induced variations in $\mathrm{NO}_{y}$, and thus $\mathrm{NO}_{x}$, in controlling the ozone QBO signal in the middle stratosphere [Chipperfield et al., 1994; Jones et al., 1998]. Chipperfield et al. [1994] concluded that the QBO modulation of $\mathrm{NO}_{2}$, via the modulated transport of $\mathrm{NO}_{y}$, is the major cause of the ozone QBO signal above $30 \mathrm{~km}$, with the temperature $\mathrm{QBO}$ effect on the ozone reaction rates being very minor. Their results were in contrast to other studies who concluded that the upper stratospheric ozone QBO signal was caused by the temperature QBO influencing the ozone loss rates [e.g., Ling and London, 1986; Zawodny and McCormick, 1991].

[39] To test these hypotheses in our model, we ran an additional simulation $(\mathrm{F})$ in which all odd nitrogen species (N, NO, $\mathrm{NO}_{2}, \mathrm{NO}_{3}, \mathrm{NO}_{2} \mathrm{O}_{5}, \mathrm{HNO}_{3}, \mathrm{CIONO}_{2}, \mathrm{BrONO}_{2}$, $\mathrm{HO}_{2} \mathrm{NO}_{2}$ ) were held constant throughout the run (the trans- port and temperature were both varied interannually as in scenario A). The resulting ozone time series and QBO signal are depicted by the dotted lines in Figures 11 and 12. This simulation reveals that without the QBO signal in $\mathrm{NO}_{y}$ and $\mathrm{NO}_{x}$, the QBO in ozone has been reduced in the middle stratosphere at $25-40 \mathrm{~km}$. The largest reduction, by a factor of two, occurs near 10 mbar. However, the ozone signal is still substantial at this level, indicating that the temperature QBO effect on the ozone loss rates (other than the $\mathrm{NO}_{x}$-induced loss) and transport, contribute significantly to the ozone interannual variability in the middle stratosphere. Figures 11 and 12 also illustrate that the non- $\mathrm{NO}_{x}$ temperature dependent photochemistry is the dominant process in driving the ozone QBO signal in the upper stratosphere at and above 3 mbar. This is revealed by the fact that keeping the $\mathrm{NO}_{x}$ species constant in scenario $\mathrm{F}$ has only a very small effect on the interannual ozone signal at these levels. These results are consistent with the findings of Ling and London [1986] and Zawodny and McCormick [1991], but appear to be somewhat in contrast with the modeling results of Chipperfield et al. [1994].

\subsection{Total Column Ozone}

[40] Figure 13 shows equatorial total column ozone $\left(10^{\circ} \mathrm{S}\right.$ to $10^{\circ} \mathrm{N}$ ) for $1993-2000$ from the new combined TOMS/ SBUV merged data set (R. S. Stolarski et al., manuscript in preparation, 2002) (light solid line-asterisk), and model scenarios A (heavy solid line), B (dashed line), and C (dotted line). The unfiltered time series (top panel) shows that the model simulations qualitatively reproduce the phase of the TOMS/SBUV seasonal cycles quite well. Consistent with the vertical profile ozone in the lower stratosphere (Figure 7, bottom), the model systematically overpredicts total ozone by 9 DU relative to TOMS/SBUV. Again, this is most likely due to a small underestimation of the strength of the model residual circulation in the lower stratosphere.

[41] The bottom panel in which the trend and seasonal cycles have been removed (a solar cycle component has also been removed from the TOMS/SBUV time series) reveals the well-known QBO signature in equatorial total ozone which has been frequently discussed in previous work [e.g., Lait et al., 1989; Bowman, 1989]. As with the seasonal cycles, all three model simulations track the phase of the observed total ozone QBO quite well. This is also shown in Table 2 which lists the QBO amplitude and phase in total ozone $\left(10^{\circ} \mathrm{S}-10^{\circ} \mathrm{N}\right)$ from the 6 model scenarios and the TOMS/SBUV data. However, consistent with the $\mathrm{CH}_{4}$ and profile ozone comparisons, all model simulations underestimate the observed total ozone QBO amplitude. This is also consistent with Figure 10, in which the QBO amplitude in profile ozone in scenarios $\mathrm{A}, \mathrm{B}$, and $\mathrm{C}$ is mostly underestimated relative to HALOE below $\sim 15$ mbar where most of the ozone resides (see also Figure 12). Scenario A (heavy solid line in Figure 13) underestimates the observed total ozone amplitude by a factor of 3. This discrepancy is somewhat improved in scenario $\mathrm{C}$ (dotted line) with the QBO temperature anomalies increased by $40 \%$, but this model simulation still underestimates the observed total ozone QBO amplitude by nearly a factor of 2 . Scenario B (dashed line), which does not have interannual variations in radiatively active constituents in the heating rate calculation, underestimates the observed QBO amplitude by about $20 \%$. 

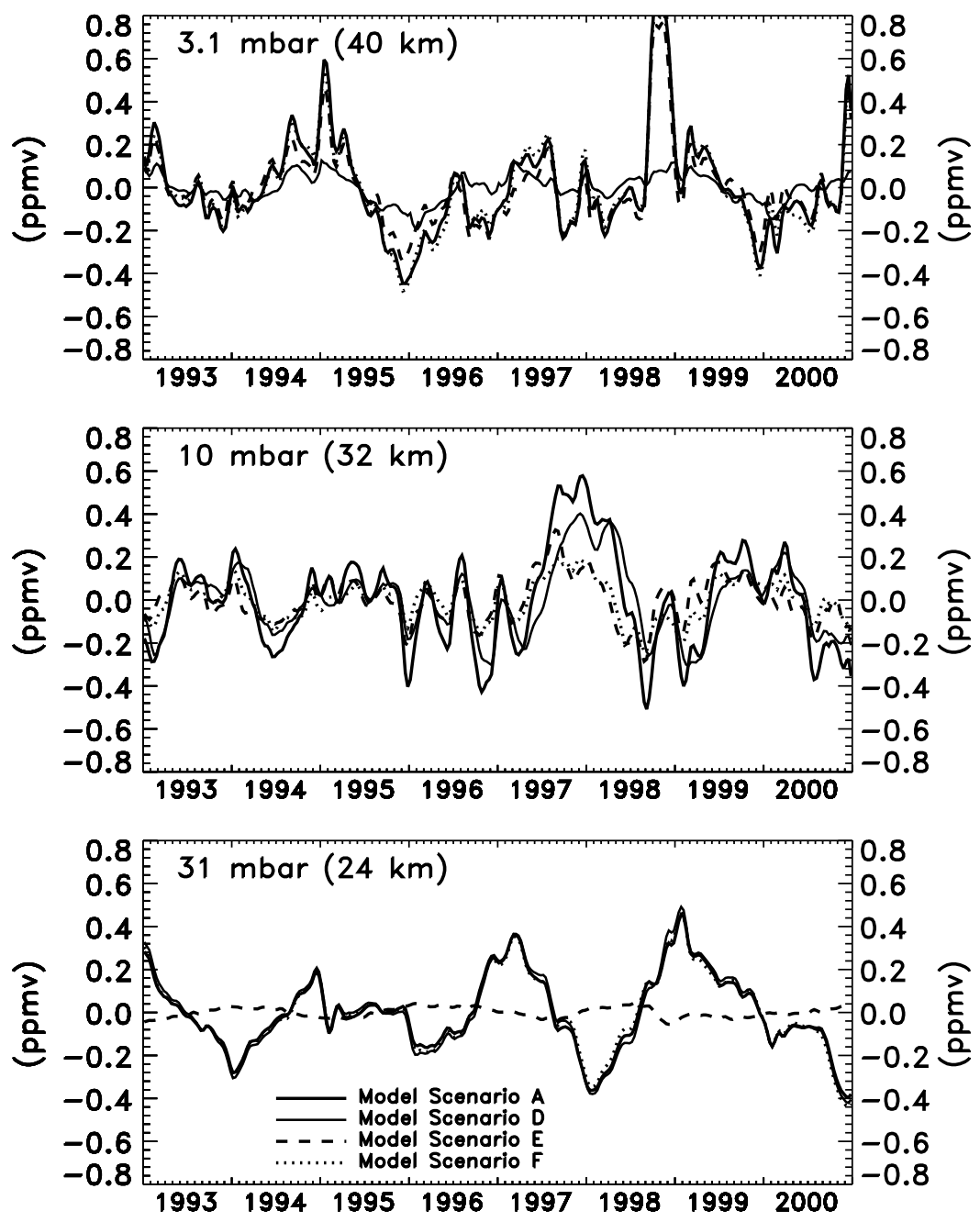

Figure 11. Time series of detrended and deseasonalized $\mathrm{O}_{3}$ from model scenarios A (heavy solid line), $\mathrm{D}$ (light solid line), $\mathrm{E}$ (dashed line), and $\mathrm{F}$ (dotted line) for $10^{\circ} \mathrm{S}-10^{\circ} \mathrm{N}$ at the altitudes indicated. The trend and seasonal cycles have been removed by regression analysis.

This illustrates that the modeled QBO amplitude in total ozone is rather sensitive to the choice of using either climatological or interannual $\mathrm{O}_{3}$ variations in the heating rate calculation.

[42] Scenario D, which only has the interannual variability in the transport (temperatures are climatological) reveals a total ozone time series (not shown) and QBO phase (Table 2) very similar to scenario A. However, without the countering effect of the temperature QBO on the reaction rates, scenario $\mathrm{D}$ reveals a slightly larger QBO amplitude in total ozone relative to scenario A (Table 2). Including only the temperature variability in scenario $\mathrm{E}$ (climatological transport) gives a very weak QBO signal in total ozone which is expectedly $180^{\circ}$ of phase with the other scenarios.

[43] We note finally that the QBO total ozone amplitude in the simulation with constant odd nitrogen species (scenario F) is actually increased slightly compared with scenario A, with almost no change in phase (Table 2). This amplitude increase appears to be in conflict with Figure 12 in which scenario $\mathrm{F}$ produced a smaller QBO amplitude in the ozone profile at almost all levels compared to scenario
A. However, this apparent contradiction can be explained by Figure 9 which illustrates that the interannual variability in ozone is strongly layered in the vertical. A reduction in the QBO amplitude in the middle stratosphere (Figure 12), where the signal is out of phase with the upper and lower stratosphere, could therefore lead to an increase in the QBO amplitude in the total column, as is the case with scenario $\mathrm{F}$.

\subsection{Age of Air}

[44] The mean age of air $(\Gamma)$ is a widely used transport diagnostic for stratospheric models [e.g., Hall et al., 1999]. The mean age can be determined from an inert tracer with a linearly time increasing tropospheric mixing ratio, such as sulfur hexafluoride $\left(\mathrm{SF}_{6}\right)$ or annually averaged $\mathrm{CO}_{2}$. Figure 14 shows vertical profiles of mean age taken from the tropical tropopause determined from balloon measurements of $\mathrm{SF}_{6}$ (triangles) and $\mathrm{CO}_{2}$ (plus signs). These data were taken at $7^{\circ} \mathrm{S}$ during February and November 1997 as part of the Observations of the Middle Stratosphere (OMS) campaign [e.g., Hall et al., 1999; Andrews et al., 2001]. Figure 14 also includes $\Gamma$ derived from in situ ER-2 

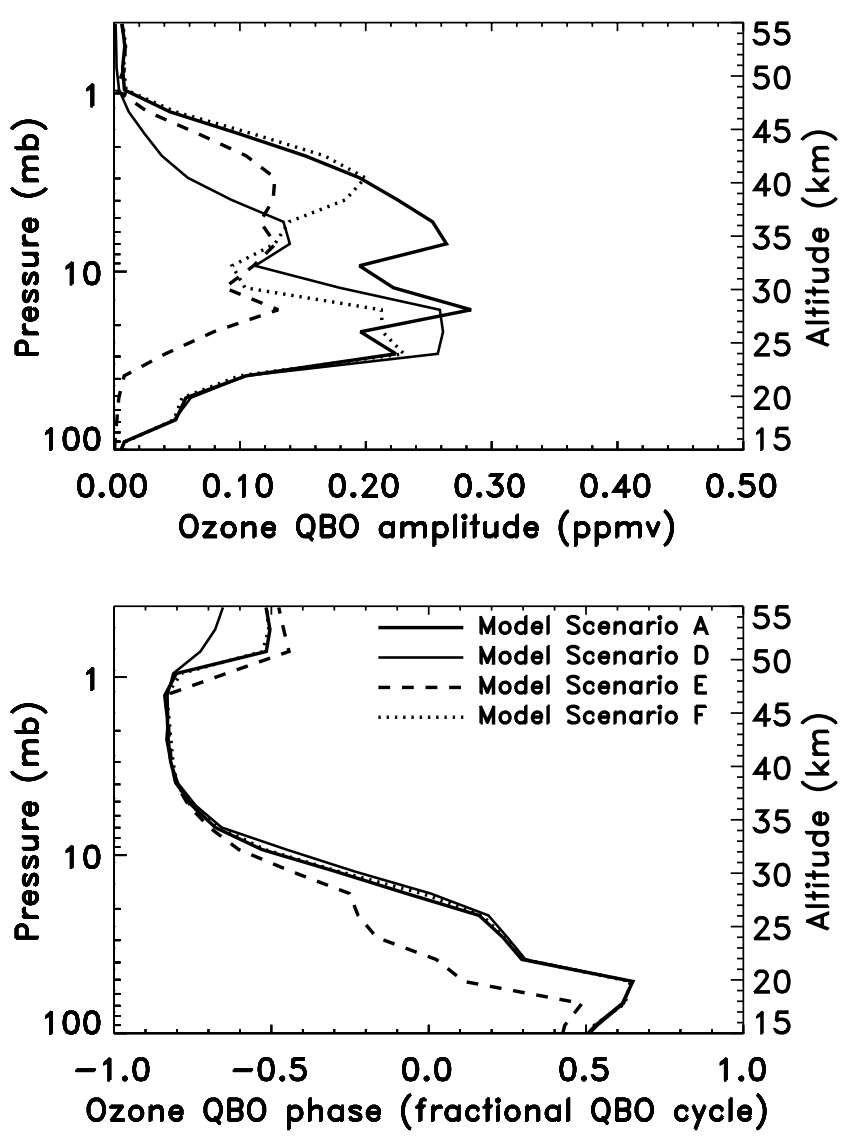

Figure 12. Vertical profiles of the QBO amplitude and phase of $\mathrm{O}_{3}$ from model scenarios A (heavy solid line), $\mathrm{D}$ (light solid line), $\mathrm{E}$ (dashed line), and $\mathrm{F}$ (dotted line) for $10^{\circ} \mathrm{S}-10^{\circ} \mathrm{N}$. See text for details concerning the QBO statistical fitting.

aircraft measurements of $\mathrm{SF}_{6}$ (square) and $\mathrm{CO}_{2}$ (asterisk) at $20 \mathrm{~km}$ averaged over several field campaigns during 1992 to 1997 for $10^{\circ} \mathrm{S}-10^{\circ} \mathrm{N}$ [Elkins et al., 1996; Andrews et al., 2001].

[45] The solid line depicts the 1993-2000 average age profile for model simulation A for $10^{\circ} \mathrm{S}-10^{\circ} \mathrm{N}$. This average profile is in good overall agreement with the observations throughout the tropical stratosphere, similar to a previous comparison with our climatological model transport [Fleming et al., 1999]. Above the tropopause, the vertical gradient in the average model $\Gamma$ is slightly weaker than indicated by the data. The model age is slightly older than the observations at $16-23 \mathrm{~km}$, and a bit younger than the data above about $23 \mathrm{~km}$. This likely reflects a small underestimation in the strength of the model tropical upwelling in the lower stratosphere and an overestimation in the middle stratosphere. The lower stratospheric bias in the model $\bar{w}^{*}$ is consistent with the lower stratospheric comparisons in Figures 4, 7, and 13 in which the model underestimated the observed $\mathrm{CH}_{4}$ and overestimated the observed profile ozone and total column ozone amounts.

[46] The dotted line in Figure 14 shows the model average $\Gamma$ for February and November 1997 at $7^{\circ} \mathrm{S}$, coincident with the OMS balloon data shown in the figure. The model bias discussed above is slightly improved in the coincident profile as the model age is slightly older, by $1-2$ months, and is closer to the data at $23-30 \mathrm{~km}$. However, this model profile is still a bit younger than the data at $26-$ $30 \mathrm{~km}$.

[47] The dashed lines in Figure 14 depict the range of the model interannual variations at each altitude over 19932000 , determined from the deseasonalized time series of $\Gamma$. The interannual range increases with altitude from near zero at the tropical tropopause to a maximum of 1.0 years at 40 $\mathrm{km}$. At this level, $\Gamma$ ranges from 4 to 5 years over the $1993-$ 2000 time period. The average $\Gamma$ reaches a maximum of 5.6 years with a range of 5.3-6 years just above $60 \mathrm{~km}$, with these values remaining nearly constant with height above this level.

[48] As with the other tracers, there are significant QBO and seasonal signals in $\Gamma$. The QBO amplitude distribution with altitude is similar to that of $\mathrm{CH}_{4}$ (Figure 6), and the seasonal variations in the model $\Gamma$ are also analogous to those in $\mathrm{CH}_{4}$ (Figure 4). The largest amplitudes of \pm 0.2 years for the QBO signal and \pm 0.28 years for the seasonal variations occur near $40 \mathrm{~km}$. However, the variations in $\Gamma$ are $180^{\circ}$ out of phase with those of methane since the vertical gradients of mean age and $\mathrm{CH}_{4}$ are reversed.

[49] We note finally that the 1993-2000 average equatorial $\Gamma$ profiles for simulations $\mathrm{B}$ and $\mathrm{C}$ are very similar to that of model simulation A in Figure 14. However, the interannual age variations in scenario $\mathrm{C}$ were slightly larger at all levels than those in scenario $\mathrm{A}$, consistent with the larger variations in equatorial $\bar{w}^{*}$ seen in Figure 3 . For the case of scenario $B$, the interannual $\Gamma$ variations were larger than scenario A only below $27 \mathrm{~km}$, again consistent with the variations in $\bar{w}^{*}$. Above $27 \mathrm{~km}$, the age variability in scenarios A and B are very similar since the vertically integrated differences in the $\bar{w}^{*} \mathrm{QBO}$ amplitudes between the two scenarios (Figure 3) tend to cancel once air parcels have reached the equatorial upper stratosphere.

\section{Summary and Conclusions}

[50] We have used UKMO meteorological data and UARS constituent data to simulate interannual dynamical variability during the 1990s in our GSFC 2-D stratospheric chemistry and transport model. Since the model is widely used to study the long term changes in stratospheric ozone, incorporating interannual variability in the simulations is important to investigate past ozone changes and the future ozone recovery. In this study, we have focused on the tropical stratosphere where eddy motions are generally weak and the mean upward velocity of the residual circulation is the dominant constituent transport mechanism. Because of this, the empirically based 2-D model framework used here adequately resolves many qualitative features of the seasonal and QBO signatures in tropical stratospheric constituent observations. The phase of the seasonal, interannual, and QBO variations observed in $\mathrm{CH}_{4}$, and profile and total column $\mathrm{O}_{3}$ data are captured quite well by the model. We also found that the QBO phase variation with altitude was relatively insensitive to the different heating rate calculations imposed in the model.

[51] Overall, the interannual and QBO amplitudes in the model simulations systematically underestimate the observations at most levels. This amplitude deficiency is partic- 


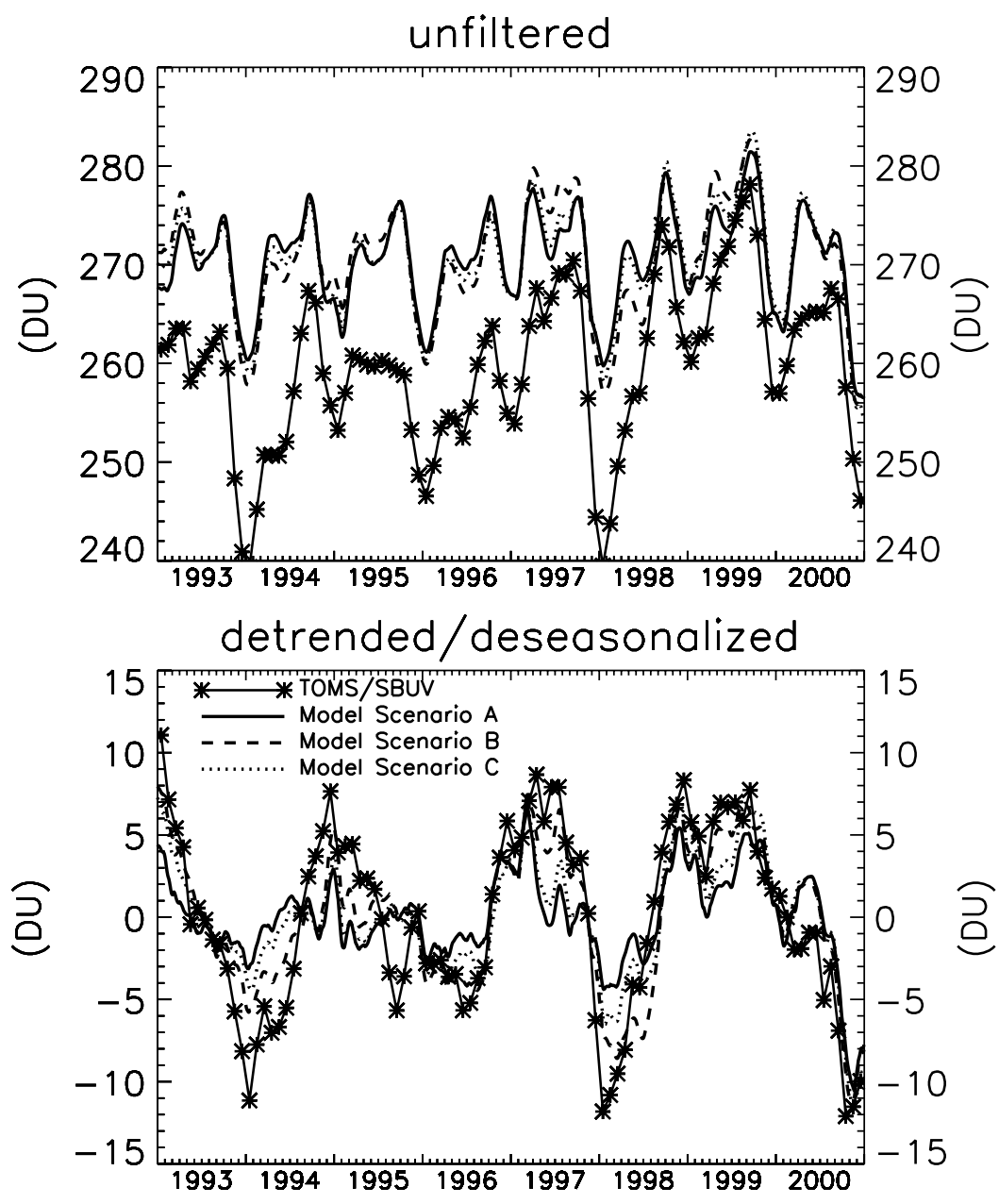

Figure 13. Top panel shows time series of total column ozone from the TOMS/SBUV merged data set (light solid line-asterisk), and model scenarios A (heavy solid line), B (dashed line), and C (dotted line) for $10^{\circ} \mathrm{S}-10^{\circ} \mathrm{N}$. Bottom panel shows the time series with the trend and seasonal cycles removed by regression analysis. A solar cycle component has also been removed from the TOMS/SBUV data.

ularly acute in the total ozone comparison. The model also did not fully resolve some of the altitudinal structure in the profile ozone QBO amplitude.

[52] These model deficiencies in resolving the QBO amplitude are probably due in part to the limited vertical resolutions of both the 2-D model and the input data sets (UKMO, UARS) used in the heating rate and dynamical calculations. The vertical grid spacing is $\sim 2 \mathrm{~km}$ in the 2-D model, $\sim 2.7 \mathrm{~km}$ for the UARS (level $3 \mathrm{~A}$ ) data, and $\sim 2.5-8$ $\mathrm{km}$ for the stratospheric UKMO data available at the standard pressure levels. Representation of the QBO (and SAO) amplitudes in the upper stratospheric UKMO analyses is further limited by the lack of direct equatorial wind observations and by the fact that the temperatures at the upper levels are largely determined by poor vertical resolution satellite radiances which underestimate the true temperature amplitudes as measured by rocketsondes [Dunkerton, 2000]. Lack of proper spatial resolution in the model and input meteorological data results in degradation of the QBO signal in the model constituent simulations. Enhancing the QBO temperature amplitudes in the UKMO data to be closer to those observed in the radiosonde data improved the model results in this regard. However, the model constituent QBO signals were still underestimated relative to the UARS data. The fact that radiative calculations may underestimate the QBO variations in the derived $\bar{w}^{*}$ relative to those derived from trace gas ascent rates [Niwano and Shiotani, 2001] could also contribute to the model deficiency in resolving the observed QBO constituent amplitudes.

[53] Sensitivity tests revealed that as expected, the QBO in transport dominates the ozone interannual variability in the lower stratosphere. The effect of the temperature QBO is dominant in the upper stratosphere via the reaction rates that control ozone destruction. Also, the $\mathrm{QBO}$ in $\mathrm{NO}_{x}$,

Table 2. Total Ozone QBO Signal Amplitude and Phase for $10^{\circ} \mathrm{S}-10^{\circ} \mathrm{N}$

\begin{tabular}{ccc}
\hline Scenario & Amplitude, DU & Phase (Fractional QBO Cycle) \\
\hline A & 2.1 & 0.28 \\
B & 5.0 & 0.32 \\
C & 3.3 & 0.31 \\
D & 2.6 & 0.27 \\
E & 0.5 & 0.74 \\
F & 2.4 & 0.26 \\
TOMS/SBUV & 6.8 & 0.29
\end{tabular}




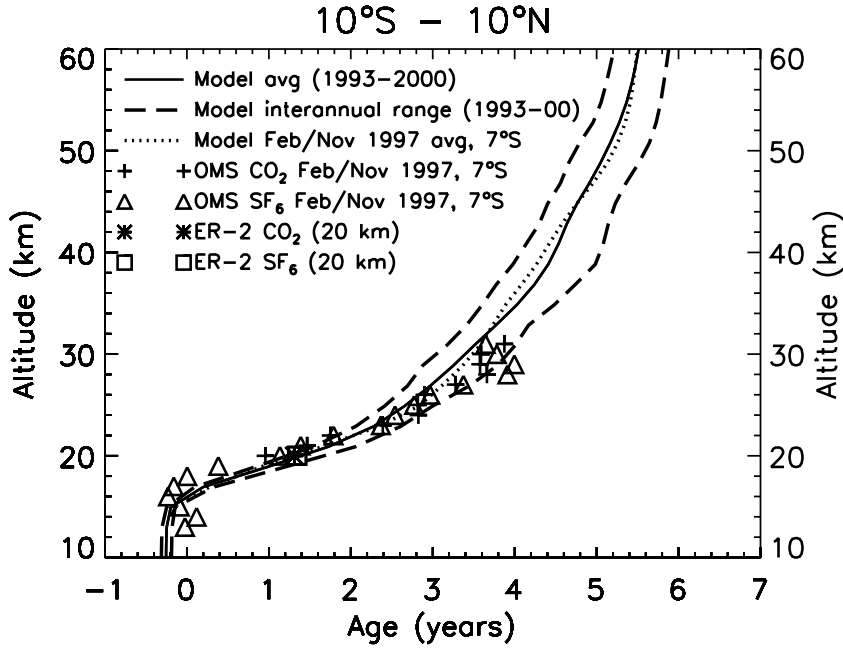

Figure 14. Vertical profiles of mean age of air at $10^{\circ} \mathrm{S}-$ $10^{\circ} \mathrm{N}$ from the model (scenario A) averaged over 19932000 (solid line), the model interannual range during 1993-2000 (dashed lines), and the model average for February and November 1997 (dotted line). Also shown are the mean age determined from OMS balloon measurements of $\mathrm{CO}_{2}$ (pluses) and $\mathrm{SF}_{6}$ (triangles) taken during February and November 1997 at $7^{\circ} \mathrm{S}$, and ER-2 aircraft measurements of $\mathrm{CO}_{2}$ (asterisk) and $\mathrm{SF}_{6}$ (square) at $20 \mathrm{~km}$ averaged over $10^{\circ} \mathrm{S}-10^{\circ} \mathrm{N}$ during $1992-1997$. Ages are taken relative to the tropical tropopause.

which is caused by the QBO modulated transport of $\mathrm{NO}_{y}$, plays a significant, but not dominant role in determining the ozone variability in the middle stratosphere between 25 and $40 \mathrm{~km}$. The impact of transport and the non-NO $\mathrm{N}_{x}$ temperature dependent ozone loss rates is substantial at these levels.

[54] The equatorial mean age of air in the model averaged over 1993-2000 is in good overall agreement with that determined from lower and middle stratospheric OMS balloon observations of $\mathrm{SF}_{6}$ and $\mathrm{CO}_{2}$ taken during 1997. The interannual variability in the model $\Gamma$ increases with altitude and maximizes near $40 \mathrm{~km}$, with a range of 4-5 years during the 1993-2000 time period. The oldest air occurs at and above $60 \mathrm{~km}$, with an altitudinally independent range of 5.3-6 years during 1993-2000.

[55] Although we have discussed only the results in the tropics in this paper, it is of significant interest to investigate the model simulations of interannual variability in the subtropics and extratropics. This will be addressed in a future study.

[56] Acknowledgments. We thank Darryn Waugh, Paul Newman, Tim Dunkerton, Jerry Ziemke, and Bill Randel for helpful discussions. We also thank the NASA Atmospheric Chemistry Modeling and Analysis Program and the UARS Science Investigation Program for support of this project.

\section{References}

Andrews, D. G., J. R. Holton, and C. B. Leovy, Middle Atmosphere Dynamics, 498 pp., Academic, San Diego, Calif., 1987.

Andrews, A. E., et al., Mean ages of stratospheric air derived from in situ observations of $\mathrm{CO}_{2}, \mathrm{CH}_{4}$, and $\mathrm{N}_{2} \mathrm{O}$, J. Geophys. Res., 106, 32,295$32,314,2001$
Angell, J. K., and J. Korshover, Quasi-biennial, annual, and semiannual zonal wind and temperature harmonic amplitudes in the stratosphere and low mesosphere of the Northern Hemisphere, J. Geophys. Res., 75, $543-$ $550,1970$.

Baldwin, M. P., et al., The quasi-biennial oscillation, Rev. Geophys., 39, 179-229, 2001

Barnett, J. J., and K. Labitzke, Climatological distribution of planetary waves in the middle atmosphere, COSPAR International Reference Atmosphere: 1986, Part II: Middle Atmosphere Models, Adv. Space Res., 10, No. 12, 63-91, 1990 .

Bowman, K. P., Global patterns of the quasi-biennial oscillation in total ozone, J. Atmos. Sci., 46, 3328-3343, 1989.

Chipperfield, M. J., Multiannual simulations with a three-dimensional chemical transport model, J. Geophys. Res., 104, 1781-1805, 1999.

Chipperfield, M. J., and L. J. Gray, Two-dimensional model studies of the interannual variability of trace gases in the middle atmosphere, J. Geophys. Res., 97, 5963-5980, 1992.

Chipperfield, M. J., L. J. Gray, J. S. Kinnersley, and J. Zawodny, A twodimensional model study of the QBO signal in SAGE II $\mathrm{NO}_{2}$ and $\mathrm{O}_{3}$, Geophys. Res. Lett., 21, 589-592, 1994.

Choi, W. K., and J. R. Holton, Transport of $\mathrm{N}_{2} \mathrm{O}$ in the stratosphere related to the equatorial semiannual oscillation, J. Geophys. Res., 96, 22,54322,557, 1991.

Considine, D. B., A. R. Douglass, and C. H. Jackman, Effects of a polar stratospheric cloud parameterization on ozone depletion due to stratospheric aircraft in a two-dimensional model, J. Geophys. Res., 99, 18,879-18,894, 1994.

Cordero, E. C., S. R. Kawa, and M. R. Schoeberl, An analysis of tropical transport: Influence of the quasi-biennial oscillation, J. Geophys. Res., $102,16,453-16,461,1997$.

Dessler, A. E., S. R. Kawa, D. B. Considine, J. W. Waters, L. Froidevaux, and J. B. Kumer, UARS measurements of CIO and $\mathrm{NO}_{2}$ at 40 and $46 \mathrm{~km}$ and implications for the model "ozone deficit", Geophys. Res. Lett., 23, $339-342,1996$

Douglass, A. R., C. H. Jackman, and R. S. Stolarski, Comparison of model results transporting the odd nitrogen family with results transporting separate odd nitrogen species, J. Geophys. Res., 94, $9862-$ 9872, 1989.

Dunkerton, T. J., The role of gravity waves in the quasi-biennial oscillation, J. Geophys. Res., 102, 26,053-26,076, 1997.

Dunkerton, T. J., Midwinter deceleration of the subtropical mesospheric jet and interannual variability of the high-latitude flow in UKMO analyses, J. Atmos. Sci., 57, 3838-3855, 2000.

Dunkerton, T. J., Quasi-biennial and subbiennial variations of stratospheric trace constituents derived from HALOE observations, J. Atmos. Sci., 58, $7-25,2001$

Dunkerton, T. J., and D. P. Delisi, Climatology of the equatorial lower stratosphere, J. Atmos. Sci., 42, 376-396, 1985.

Elkins, J. W., et al., Airborne gas chromatograph for in situ measurements of long-lived species in the upper troposphere and lower stratosphere, Geophys. Res. Lett., 23, 347-350, 1996.

Eluszkiewicz, J., and M. Allen, A global analysis of the ozone deficit in the upper stratosphere and lower mesosphere, J. Geophys. Res., 98, 10691082, 1993.

Eluszkiewicz, J., et al., Residual circulation in the stratosphere and lower mesosphere as diagnosed from microwave limb sounder data, J. Atmos. Sci., 53, 217-240, 1996

Fleming, E. L., S. Chandra, J. J. Barnett, and M. Corney, Zonal mean temperature, pressure, zonal wind, and geopotential height as functions of latitude, COSPAR International Reference Atmosphere: 1986, Part II: Middle Atmosphere Models, Adv. Space Res., 10, No. 12, 11-59, 1990.

Fleming, E. L., C. H. Jackman, R. S. Stolarski, and D. B. Considine, Simulation of stratospheric tracers using an improved empirically based two-dimensional model transport formulation, J. Geophys. Res., 104, 23,911-23,934, 1999

Garcia, R. R., and S. Solomon, A numerical model of the zonally averaged dynamical and chemical structure of the middle atmosphere, J. Geophys. Res., 88, 1379-1400, 1983.

Garcia, R. R., T. J. Dunkerton, R. S. Lieberman, and R. A. Vincent, Climatology of the semiannual oscillation of the tropical middle atmosphere, J. Geophys. Res., 102, 26,019-26,032, 1997.

Gray, L. J., and M. P. Chipperfield, On the interannual variability of trace gases in the middle atmosphere, Geophys. Res. Lett., 17, 933-936, 1990.

Gray, L. J., and T. J. Dunkerton, The role of the seasonal cycle in the quasibiennial oscillation of ozone, J. Atmos. Sci., 47, 2429-2451, 1990.

Gray, L. J., and J. A. Pyle, Two-dimensional model studies of equatorial dynamics and tracer distributions, Q. J. R. Meteorol. Soc., 113, 635-651, 1987.

Gray, L. J., and J. A. Pyle, A two-dimensional model of the quasi-biennial oscillation of ozone, J. Atmos. Sci., 46, 203-220, 1989. 
Gray, L. J., and J. M. Russell III, Interannual variability of trace gases in the subtropical winter stratosphere, J. Atmos. Sci., 56, 977-993, 1999.

Gray, L. J., and S. Ruth, The modeled latitudinal distribution of the ozone quasi-biennial oscillation using observed equatorial winds, J. Atmos. Sci., 50, $1033-1046,1993$.

Hall, T. M., D. W. Waugh, K. A. Boering, and R. A. Plumb, Evaluation of transport in stratospheric models, J. Geophys. Res., 104, 18,815-18,839, 1999.

Hamilton, K., R. J. Wilson, and R. S. Hemler, Middle atmosphere simulated with high vertical and horizontal resolution versions of a GCM: Improvements in the cold pole bias and generation of a QBO-like oscillation in the tropics, J. Atmos. Sci., 56, 3829-3846, 1999.

Hasebe, F., Quasi-biennial oscillations of ozone and diabatic circulation in the equatorial stratosphere, J. Atmos. Sci., 51, 729-745, 1994.

Holton, J. R., and H. C. Tan, The influence of the equatorial quasi-biennial oscillation on the global circulation at $50 \mathrm{mb}$, J. Atmos. Sci., 37, $2200-$ 2208, 1980 .

Holton, J. R., and X. Zhu, A further study of gravity wave induced drag and diffusion in the mesosphere, J. Atmos. Sci., 41, 2653-2662, 1984.

Huang, T. Y. W., and A. K. Smith, The mesospheric diabatic circulation and the parameterized thermal effect of gravity wave breaking on the circulation, J. Atmos. Sci., 48, 1093-1111, 1991.

Jackman, C. H., A. R. Douglass, R. B. Rood, R. D. McPeters, and P. E. Meade, Effect of solar proton events on the middle atmosphere during the past two solar cycles as computed using a two-dimensional model, J. Geophys. Res., 95, 7417-7428, 1990.

Jackman, C. H., A. R. Douglass, S. Chandra, R. S. Stolarski, J. E. Rosenfield, J. A. Kaye, and E. R. Nash, Impact of interannual variability (1979-1986) of transport and temperature on ozone as computed using a two-dimensional photochemical model, J. Geophys. Res., 96, 50735079, 1991 .

Jackman, C. H., E. L. Fleming, S. Chandra, D. B. Considine, and J. E. Rosenfield, Past, present, and future modeled ozone trends with comparisons to observed trends, J. Geophys. Res., 101, 28,753-28,767, 1996.

Jones, D. B. A., H. R. Schneider, and M. B. McElroy, Effects of the quasibiennial oscillation on the zonally averaged transport of tracers, J. Geophys. Res., 103, 11,235-11,249, 1998.

Kennaugh, R., S. Ruth, and L. J. Gray, Modeling quasi-biennial variability in the semiannual double peak, J. Geophys. Res., 102, 16,169-16,187, 1997.

Kinnersley, J. S., and K. K. Tung, Modeling the global interannual variability of ozone due to the equatorial QBO and to extratropical planetary wave activity, J. Atmos. Sci., 55, 1417-1428, 1998.

Kinnersley, J. S., and K. K. Tung, Mechanisms for the extratropical QBO in circulation and ozone, J. Atmos. Sci., 56, 1942-1962, 1999.

Lait, L. R., M. R. Schoeberl, and P. A. Newman, Quasi-biennial modulation of the Antarctic ozone depletion, J. Geophys. Res., 94, 11,559-11,571, 1989.

Lindzen, R. S., Turbulence and stress owing to gravity wave and tidal breakdown, J. Geophys. Res., 86, 9707-9714, 1981.

Ling, X. D., and J. London, The quasi-biennial oscillation of ozone in the tropical middle stratosphere: A one-dimensional model, J. Atmos. Sci. 43, 3122-3137, 1986.

Minschwaner, K., R. J. Salawitch, and M. B. McElroy, Absorption of solar radiation by $\mathrm{O}_{2}$ : Implications for $\mathrm{O}_{3}$ and lifetimes of $\mathrm{N}_{2} \mathrm{O}, \mathrm{CFCI}_{3}$, and $\mathrm{CF}_{2} \mathrm{CI}_{2}, J$. Geophys. Res., 98, 10,543-10,561, 1993.

Nagashima, T., M. Takahashi, and F. Hasebe, The first simulation of an ozone QBO in a general circulation model, Geophys. Res. Lett., 25, $3131-3134,1998$.

Nash, J., Extension of explicit radiance observations by the stratospheric sound unit into the lower stratosphere and lower mesosphere, $Q . J . R$. Meteorol. Soc., 114, 1153-1171, 1988 .

Naujokat, B., An update of the observed quasi-biennial oscillation of the stratospheric winds over the Tropics, J. Atmos. Sci., 43, 1873-1877, 1986.

Newell, R. E., J. W. Kidson, D. G. Vincent, and G. J. Boer, The General Circulations of the Tropical Atmosphere, vol. 2, chap. 7, MIT Press, Cambridge, Mass., 1974.
Niwano, M., and M. Shiotani, Quasi-biennial oscillation in vertical velocity inferred from trace gas data in the equatorial lower stratosphere, J. Geophys. Res., 106, 7281-7290, 2001.

Ortland, D. A., W. R. Skinner, P. B. Hays, M. D. Burrage, R. S. Lieberman, A. R. Marshall, and D. A. Gell, Measurements of stratospheric winds by the high resolution Doppler imager, J. Geophys. Res., 101, 10,35110,363, 1996.

O'Sullivan, D., and T. J. Dunkerton, The influence of the quasi-biennial oscillation on global constituent distributions, J. Geophys. Res., 102, 21,731-21,743, 1997 .

Randel, W. J., and J. B. Cobb, Coherent variations of monthly mean total ozone and lower stratospheric temperature, J. Geophys. Res., 99, 54335447, 1994.

Randel, W. J., and R. R. Garcia, Application of a planetary wave breaking parameterization to stratospheric circulation statistics, J. Atmos. Sci., 51, 1157-1168, 1994.

Randel, W. J., and F. Wu, Isolation of the ozone QBO in SAGE II data by singular-value decomposition, J. Atmos. Sci., 53, 2546-2559, 1996.

Randel, W. J., B. A. Boville, J. C. Gille, P. L. Bailey, S. T. Massie, J. B. Kumer, J. L. Mergenthaler, and A. E. Roche, Simulation of stratospheric $\mathrm{N}_{2} \mathrm{O}$ in the NCAR CCM2: Comparison with CLAES data and global budget analysis, J. Atmos. Sci., 51, 2834-2845, 1994.

Randel, W. J., F. Wu, J. M. Russell III, A. Roche, and J. W. Waters, Seasonal cycles and QBO variations in stratospheric $\mathrm{CH}_{4}$ and $\mathrm{H}_{2} \mathrm{O}$ observed in UARS HALOE data, J. Atmos. Sci., 55, 163-185, 1998.

Randel, W. J., F. Wu, R. Swinbank, J. Nash, and A. O’Neill, Global QBO circulation derived from UKMO stratospheric analyses, J. Atmos. Sci., 56, 457-474, 1999

Reed, R. J., A tentative model of the 26 month oscillation in tropical latitudes, Q. J. R. Meteorol. Soc., 90, 665-674, 1964.

Reed, R. J., W. J. Campbell, L. A. Rasmussen, and D. G. Rodgers, Evidence of a downward-propagating annual wind reversal in the equatorial stratosphere, J. Geophys. Res., 66, 813-818, 1961.

Rosenfield, J. E., P. A. Newman, and M. R. Schoeberl, Computations of diabatic descent in the stratospheric polar vortex, J. Geophys. Res., 99, $16,677-16,689,1994$

Ruth, S., R. Kennaugh, L. J. Gray, and J. M. Russell III, Seasonal, semiannual, and interannual variability seen in measurements of methane made by the UARS Halogen Occultation Experiment, J. Geophys. Res., 102, 16,189-16,199, 1997.

Sander, S. P., et al., Chemical kinetics and photochemical data for use in stratospheric modeling, Supplement to Evaluation 12: Update of key reactions, Evaluation 13, JPL Publ. 00-3, 74 pp., 2000.

Schoeberl, M. R., D. F. Strobel, and J. P. Apruzese, A numerical model of gravity wave breaking and stress in the mesosphere, J. Geophys. Res., 88, 5249-5259, 1983.

Tung, K. K., and H. Yang, Global QBO in circulation and ozone, part I, Reexamination of observational evidence, J. Atmos. Sci., 51, 2699-2707, 1994.

Veryard, R. G., and R. A. Ebdon, Fluctuations in tropical stratospheric winds, Meteorol. Mag., 90, 125-143, 1961.

Wallace, J. M., R. L. Panetta, and J. Estberg, Representation of the equatorial stratospheric quasi-biennial oscillation in EOF phase space, J. Atmos. Sci., 50, 1751-1762, 1993.

World Meteorological Organization (WMO), Scientific assessment of ozone depletion: 1998, Rep. 44, Global Ozone Res. and Monit. Proj., Geneva, 1999.

Zawodny, J. M., and M. P. McCormick, Stratospheric aerosol and gas experiment II measurements of the quasi-biennial oscillations in ozone and nitrogen dioxide, J. Geophys. Res., 96, 9371-9377, 1991.

D. B. Considine, NASA Langley Research Center, Mail Stop 401B, Hampton, VA 23681, USA.

E. L. Fleming, C. H. Jackman, and J. E. Rosenfield, NASA Goddard Space Flight Center, Code 916, Greenbelt Road, Greenbelt, MD 207710001, USA. (fleming@kahuna.gsfc.nasa.gov) 